\section{5 years of research on business intelligence process: a synthesis of a fragmented literature}

\section{Business intelligence process}

School of Management, University of Vaasa, Vaasa, Finland, and

Marko Kohtamäki

School of Management, University of Vaasa, Vaasa, Finland; USN Business

School, University of South-Eastern Norway, Kongsberg, Norway and

Department of Entrepreneurship and Innovation, Lulea University of Technology, Luleå, Sweden
Received 3 July 2020 Revised 2 September 2020 Accepted 20 September 2020

\begin{abstract}
Purpose - The business intelligence (BI) research witnessed a proliferation of contributions during the past three decades, yet the knowledge about the interdependencies between the BI process and organizational context is scant. This has resulted in a proliferation of fragmented literature duplicating identical endeavors. Although such pluralism expands the understanding of the idiosyncrasies of BI conceptualizations, attributes and characteristics, it cannot cumulate existing contributions to better advance the BI body of knowledge. In response, this study aims to provide an integrative framework that integrates the interrelationships across the BI process and its organizational context and outlines the covered research areas and the underexplored ones.
\end{abstract}

Design/methodology/approach - This paper reviews 120 articles spanning the course of 35 years of research on BI process, antecedents and outcomes published in top tier ABS ranked journals.

Findings - Building on a process framework, this review identifies major patterns and contradictions across eight dimensions, namely, environmental antecedents; organizational antecedents; managerial and individual antecedents; BI process; strategic outcomes; firm performance outcomes; decision-making; and organizational intelligence. Finally, the review pinpoints to gaps in linkages across the BI process, its antecedents and outcomes for future researchers to build upon.

Practical implications - This review carries some implications for practitioners and particularly the role they ought to play should they seek actionable intelligence as an outcome of the BI process. Across the studies this review examined, managerial reluctance to open their intelligence practices to close examination was omnipresent. Although their apathy is understandable, due to their frustration regarding the lack of measurability of intelligence constructs, managers manifestly share a significant amount of responsibility in turning out explorative and descriptive studies partly due to their defensive managerial participation. Interestingly, managers would rather keep an ineffective BI unit confidential than open it for assessment in fear of competition or bad publicity. Therefore, this review highlights the value open participation of managers in longitudinal studies could bring to the BI research and by extent the new open intelligence culture across their organizations where knowledge is overt, intelligence is participative, not selective and where double loop learning alongside scholars is

(C) Yassine Talaoui and Marko Kohtamaki. Published by Emerald Publishing Limited. This article is published under the Creative Commons Attribution (CC BY 4.0) licence. Anyone may reproduce, distribute, translate and create derivative works of this article (for both commercial and non-commercial purposes), subject to full attribution to the original publication and authors. The full terms of this licence may be seen at http://creativecommons.org/licences/by/4.0/ legalcode 
MRR 44,5

continuous. Their commitment to open participation and longitudinal studies will help generate new research that better integrates the BI process within its context and fosters new measures for intelligence performance.

Originality/value - This study provides an integrative framework that integrates the interrelationships across the BI process and its organizational context and outlines the covered research areas and the underexplored ones. By so doing, the developed framework sets the ground for scholars to further develop insights within each dimension and across their interrelationships.

Keywords Business intelligence, Literature review, Synthesis, Process, Antecedents, Outcomes

Paper type Literature review

\section{Introduction}

The business intelligence (BI) process research has grown exponentially during the past three decades into a fragmented state drawing from a diverse set of studies with widely different contributions (Talaoui and Kohtamäki, 2020). Although this pluralism is necessary for the BI process research to generate momentum from insightful findings, it can yield a disjointed theoretical progress if it lacks proper literature reviews that uncover what is already known and set a direction for the way ahead (Hart, 1998; Rowe, 2014). Unfortunately, extant reviews of the BI process research still focus on the scheme that BI follows to provide actionable intelligence for organizations to act upon (Jourdan et al., 2008) rather than the context where this process occurs and guide organizations (Bingham and Eisenhardt, 2011; Loock and Hinnen, 2015). For instance, the stock of previous reviews on BI research focused on its attributes and conceptualization (Ekbia et al., 2015), its methodologies and research strategies (Jourdan et al., 2008), its application to operations models (Roden et al., 2017), its contribution to business value (Trieu, 2017) or decisionmaking (Mora et al., 2005), its dimensions and taxonomy (Holsapple et al., 2014), its usage (Watson and Wixom, 2007), its field development (Arnott and Pervan, 2005, 2014; Toit, 2015), its attitudes (Rouach and Santi, 2001), its characteristics and applications (Chen et al., 2012; Eom and Kim, 2006; Moro et al., 2015), its technologies and challenges (Shim et al., 2002; Sivarajah et al., 2017) and its trends (Watson, 2009).

To this date, no literature review has examined the BI process and its interrelationships with the organizational context. To address this gap, our paper synthesizes the body of knowledge of the BI process to discern patterns of the interrelated relationships of its characteristics, and its context, i.e. antecedents and outcomes (Hutzschenreuter and Kleindienst, 2006; Rajagopalan et al., 1993; Van De Ven, 1992). We follow other scholars' conceptualization of BI process as an integrative sequence that encompasses the collection, transformation and usage (Chen et al., 2012; Davenport and Paul Barth, 2012; Trieu, 2017) that occurs in an organizational context, exerts an influence upon it and is shaped by its antecedents (Bingham and Eisenhardt, 2011; Loock and Hinnen, 2015).

To capture the BI process within its context, we follow the process framework of Hutzschenreuter and Kleindienst (2006), Rajagopalan et al. (1993) and Van De Ven (1992) for it allows to position the BI process within its organizational context and explore their interrelated linkages. In this vein, we purposefully follow Levy and Ellis (2006) and Webster and Watson (2002)'s "effective methodology" of conducting systematic reviews in crossdisciplinary research such as the BI process body of knowledge and adheres to its processual scheme to select 120 articles published in top tier ABS ranked journals that we synthesize and integrate drawing from the process view framework that emphasizes the role of organizational context (Hutzschenreuter and Kleindienst, 2006; Rajagopalan et al., 1993; Fischer et al., 2016; Vaara and Lamberg, 2014). By so doing, we seek to synthesize the 
contributions of prior studies on the BI process and its organizational context and pinpoint to gaps in linkages across the BI process, its antecedents and outcomes for future researchers to build upon. The paper begins with a detailed explanation of our systematic method, then presents our synthetic review and concludes with research gaps for further studies.

\section{Methodology}

We follow the systematic review scheme of Levy and Ellis (2006) to offer the BI research in particular and IS field what Webster and Watson (2002, p. 14) refer to as "effective methodological review". According to Levy and Ellis (2006), an effective review should justify its contribution to a body of knowledge being reviewed, synthesize quality research and present a sound research framework and systematic papers' selection method. Our choice of Levy and Ellis (2006)'s systematic review scheme is twofold:

- It addresses the peculiar and cross-disciplinary nature of the IS research in general and the BI body of knowledge in particular.

- It follows a process protocol of literature reviews that fits our process perspective of integrating the BI body of knowledge.

Following Levy and Ellis (2006), a high-quality input yields a high-quality output if it adheres to comprehensiveness, quality and relevance inclusion criteria. To ensure comprehensiveness, we go beyond the IT contributions on BI and extend our search scope beyond one database to capture all fruitful work regardless of its inherent discipline (Levy and Ellis, 2006). We, therefore, use four scientific databases, reputable among scholars of management, marketing and information management fields, namely, ABI/Inform, EBSCO academic search elite, EBSCO business premier, Emerald journals (Levy and Ellis, 2006; Webster and Watson, 2002). We conducted a pilot search of keywords in the aforementioned databases with two keywords, namely, BI and competitive intelligence. The intention of this trial was to gather all keywords related to both concepts. In total, 26 keywords were deemed appropriate for this review. Boolean operators ("AND" and "OR") and the asterisk "*” wildcard were used to concatenate the keywords set to generate multiple query strings that returned 11,745 hits across the four databases from 1985 through 2020 as Table 1 depicts. We selected 1990 as a starting year of our search as it represents the inception of BI (Chen et al., 2012; Davenport et al., 2001). A first scrutiny of the hits sought the elimination of duplicates shrinking the set of papers to 780 including conference papers, which we excluded because their research rigor is inferior to top journals and are not subjected to a rigorous peer review process (Culnan, 1978; Levy and Ellis, 2006; Webster and Watson, 2002). Besides, the high quality input criterion Levy and Ellis (2006) and Webster and Watson (2002) impose limits our sample to articles published in high quality peer reviewed journals of a reputable ranking because they are likely to contain the major contributions we ought to deal with to ensure rigor and leading theoretical discussions on BI (Levy and Ellis, 2006; Vogel, 2012; Webster and Watson, 2002). Therefore, we chose the ABS journal ranking because it offers an extensive cross-disciplinary list that is corroborated by a documented hybrid and iterative ranking process based upon peer reviews, peers' consensus and citations (Mingers and Willcocks, 2017; Morris et al., 2009), which, in turn, offers us a credible guide that we can gauge papers against with confidence (Levy and Ellis, 2006; Morris et al., 2009; Webster and Watson, 2002). This high-quality criterion reduced our sample to 290 articles whose abstracts we read and evaluated against our relevance criterion that, based on the research gap and motivation, deems only articles addressing BI process, antecedents or outcomes relevant to the review at hand. This step reduced the sample to 113 


\section{MRR 44,5}

Table 1.

Systematic selection process of the articles

\section{Search strings}

TITLE-ABS-KEY ("business intelligence" OR "business intelligence model*" OR "competitive intelligence" OR "market intelligence" OR "executive information system*” OR "decision support system*" OR "business analytic*” OR "data mining” OR "data*warehous*” OR "online*analytic*processing” OR "extract*transform*load” OR "environment* scanning” OR “customer intelligence” OR "environment* analy*i*” OR "finance* intelligence" OR "structured query language” OR "relational database management system*" OR "data mart” OR "data discovery" OR "dashboard” OR "process mining” OR "complex event processing” OR "prescriptive analytics" OR "predictive analytic*” OR "big data” OR "big data analytic*”) $\mathrm{ABI} / \mathrm{INFORM}$

EBSCO ACADEMIC SEARCH ELITE

9,927

EBSCO BUSINESS PREMIER

270

EMERALD JOURNALS

1,192

Total hits

356

Minus duplicates

11,745

780

ABS top tier journals

290

$\begin{array}{lr}\text { Articles addressing BI process, antecedents or outcomes } & 113 \\ \text { Backward referencing } & \text { plus } 7\end{array}$

Final sample

articles that contain one or several linkages to the BI process, antecedents or outcomes. To verify the comprehensiveness of our sample and prevent the exclusion of any older and relevant contribution, we conducted a backward search that consists of reviewing the reference lists in our final set of papers to identify any work that our time frame criterion might have excluded and/or that our databases search might not have revealed (Bandara et al., 2015; Levy and Ellis, 2006; Müller and Jensen, 2017; Thennakoon et al., 2018; Webster and Watson, 2002). Our backward search analyzed each title in the reference lists of the 113 articles and identified 7 seminal works published prior to 1990 such as El Sawy (1985) and Ghoshal and Kim (1986), which, in turn, extended our final sample to 120 articles. We gauged the census of this review complete when no new concepts or relationships were identified in the literature set (Levy and Ellis, 2006; Webster and Watson, 2002).

\section{A synthetic framework of the business intelligence process}

According to Levy and Ellis (2006) and Webster and Watson (2002), a good literature review offers a complete census of its synthesis and follows an analytical framework to structure the body of knowledge it deals with. As a corollary, we followed the process linkage exploring framework of Hutzschenreuter and Kleindienst (2006) and Rajagopalan et al. (1993) because it emphasizes the role of organizational context (Vaara and Lamberg, 2014) and the mediating mechanisms that reveal the causality between antecedents and outcomes (Fischer et al., 2016). We coded all articles using a two-digit key (01-120) that we plotted in Table 2 to provide summaries of the studies. Our thorough review of the 120 articles revealed shared patterns along which three streams were discernable, namely, antecedents, BI process and outcomes. In addition, our analysis revealed that each article focused on different interrelationships across the organizational context of the BI process. For the sake of comprehensiveness and in-depth analysis, we marked each article with a linkage code composed of a letter designating the contextual domain [(1) antecedents; (2) BI process; and (3) outcome] and a number that refers to the factor responsible of the relationship between contextual domains: 


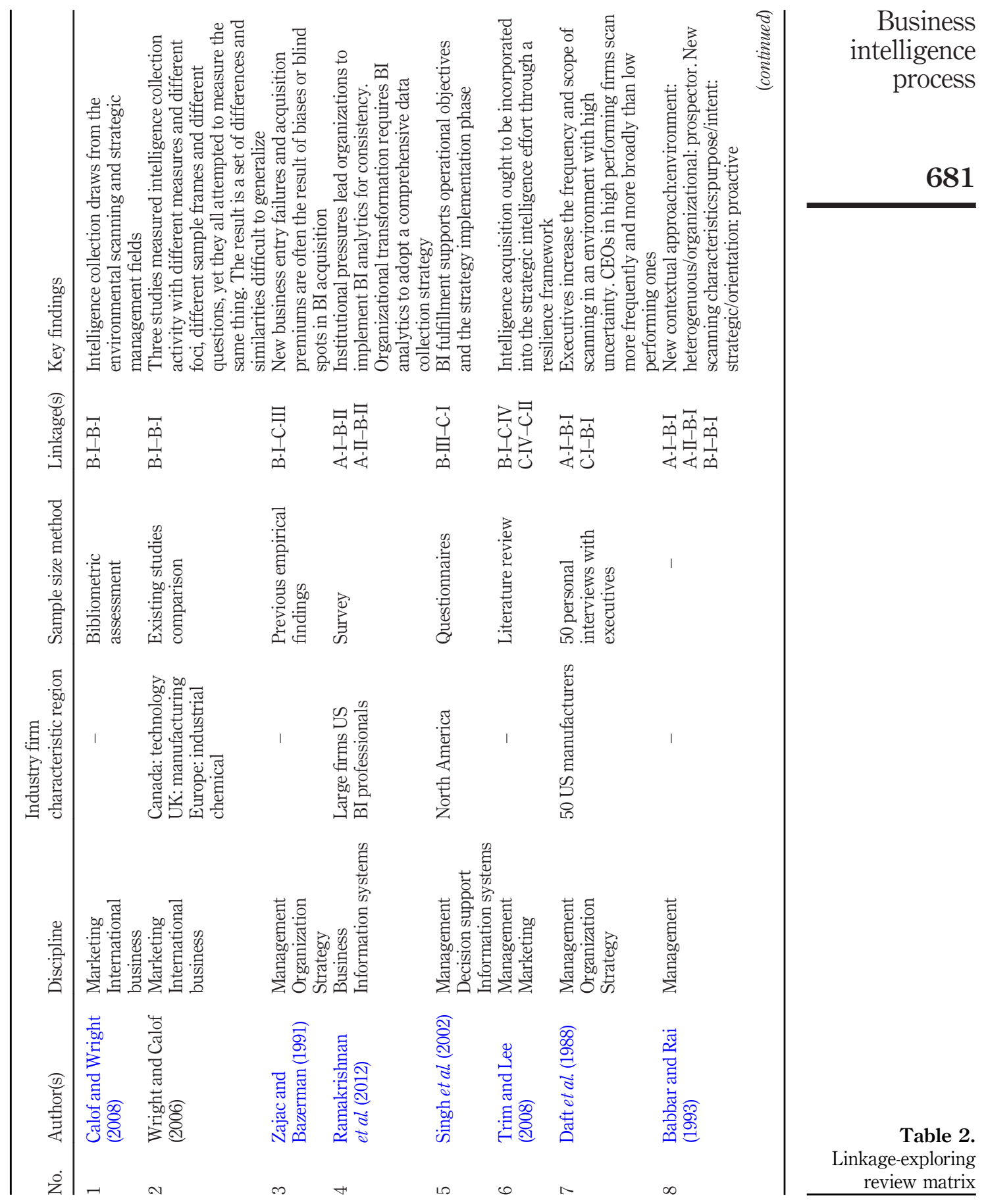




\begin{tabular}{l} 
MRR \\
44,5 \\
682 \\
\hline
\end{tabular}

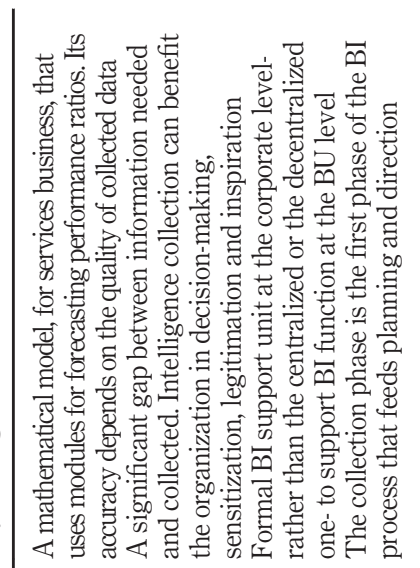

﨎

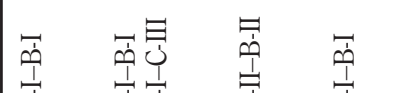

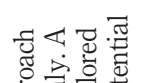<smiles>C1CCCCC1</smiles>

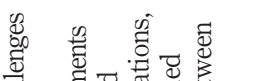

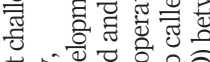

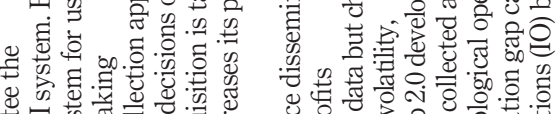

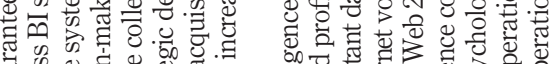

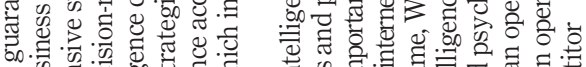
on. a पै

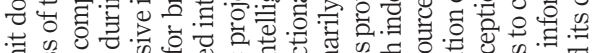

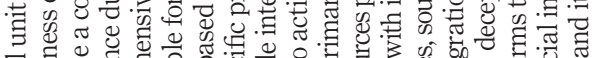

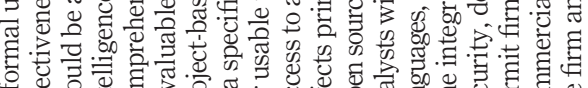

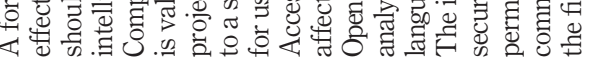

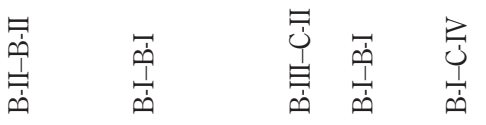

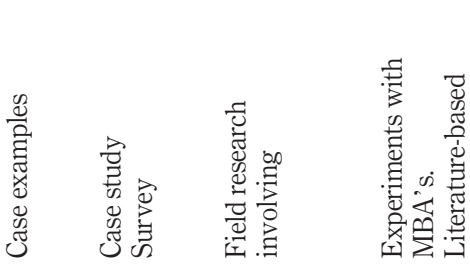

ம $\dot{\varphi}$

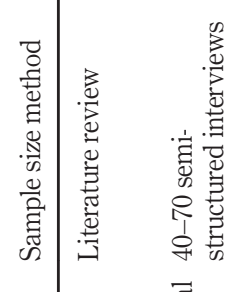

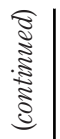

营

त्త్ర (

:

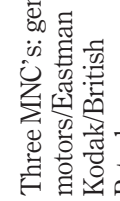

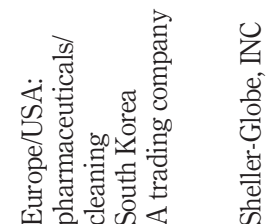

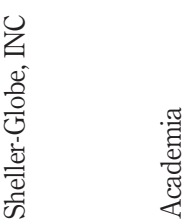
悹<smiles>CCCC</smiles>

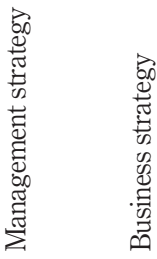

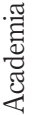

Table 2.

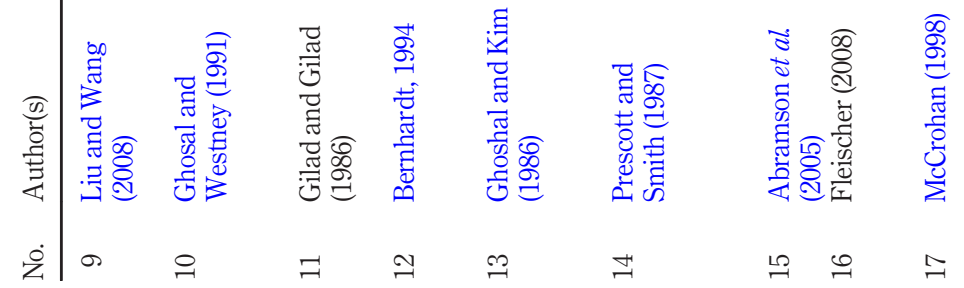




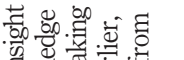

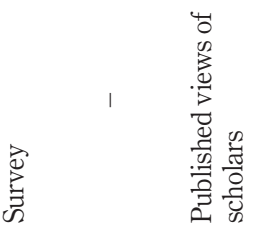

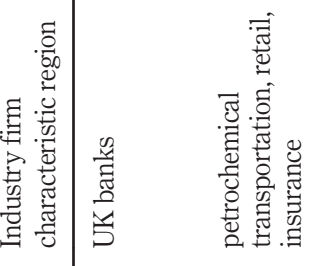

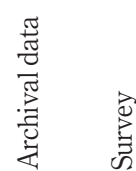

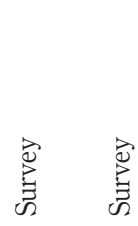


MRR

44,5

684

Table 2.

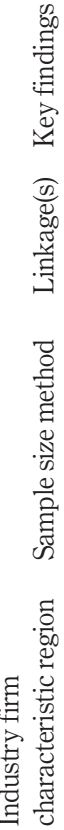

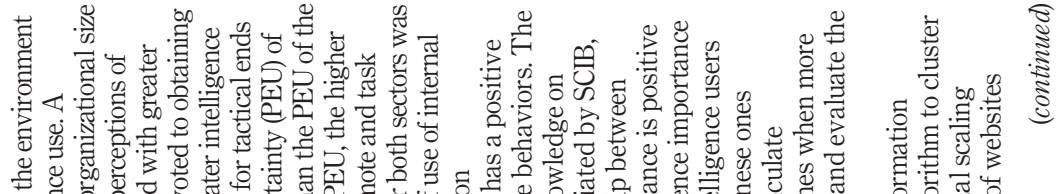

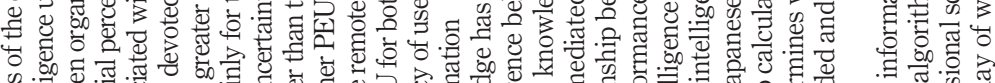

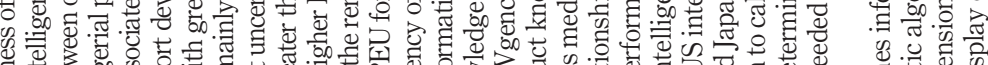

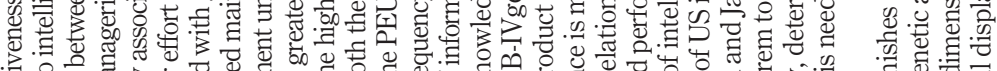

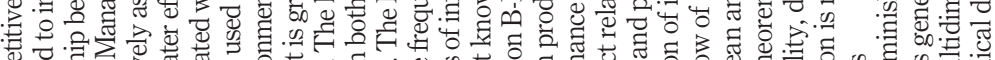

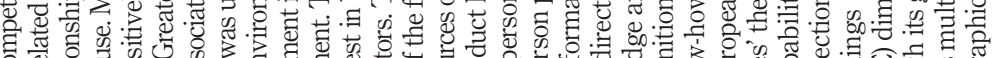

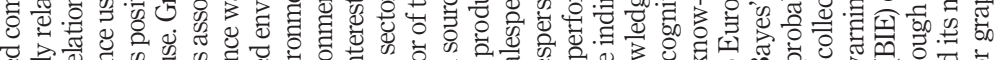

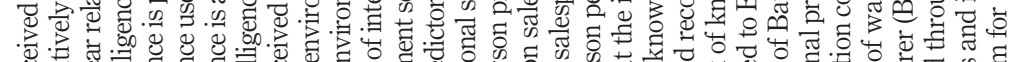

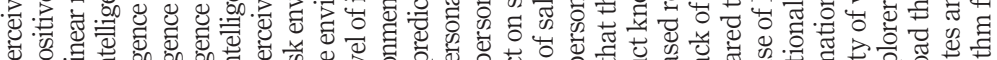

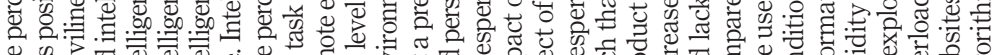

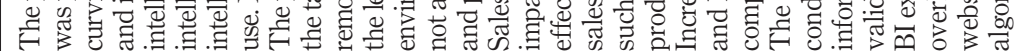

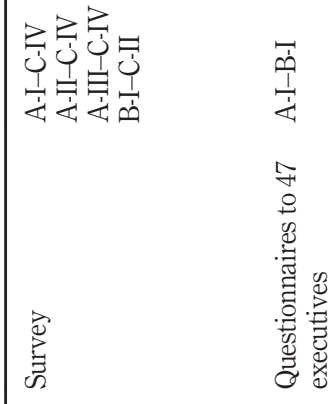

寻录 它 它

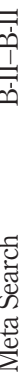

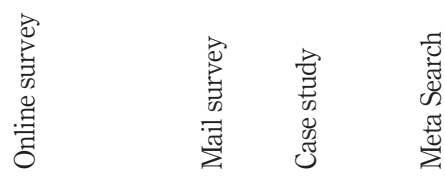

(1)

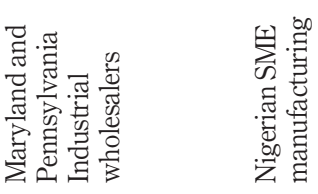

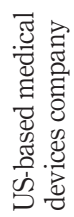

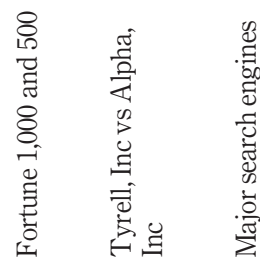

:

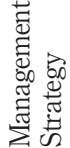

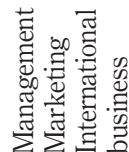

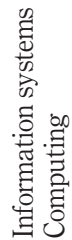

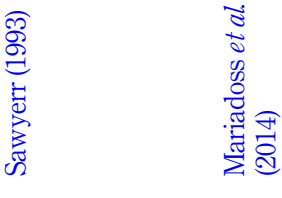

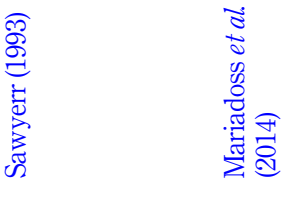

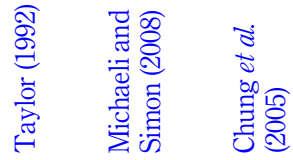

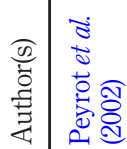

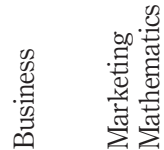

ลิ

$\stackrel{\Im}{ง}$

ล ค

ल 


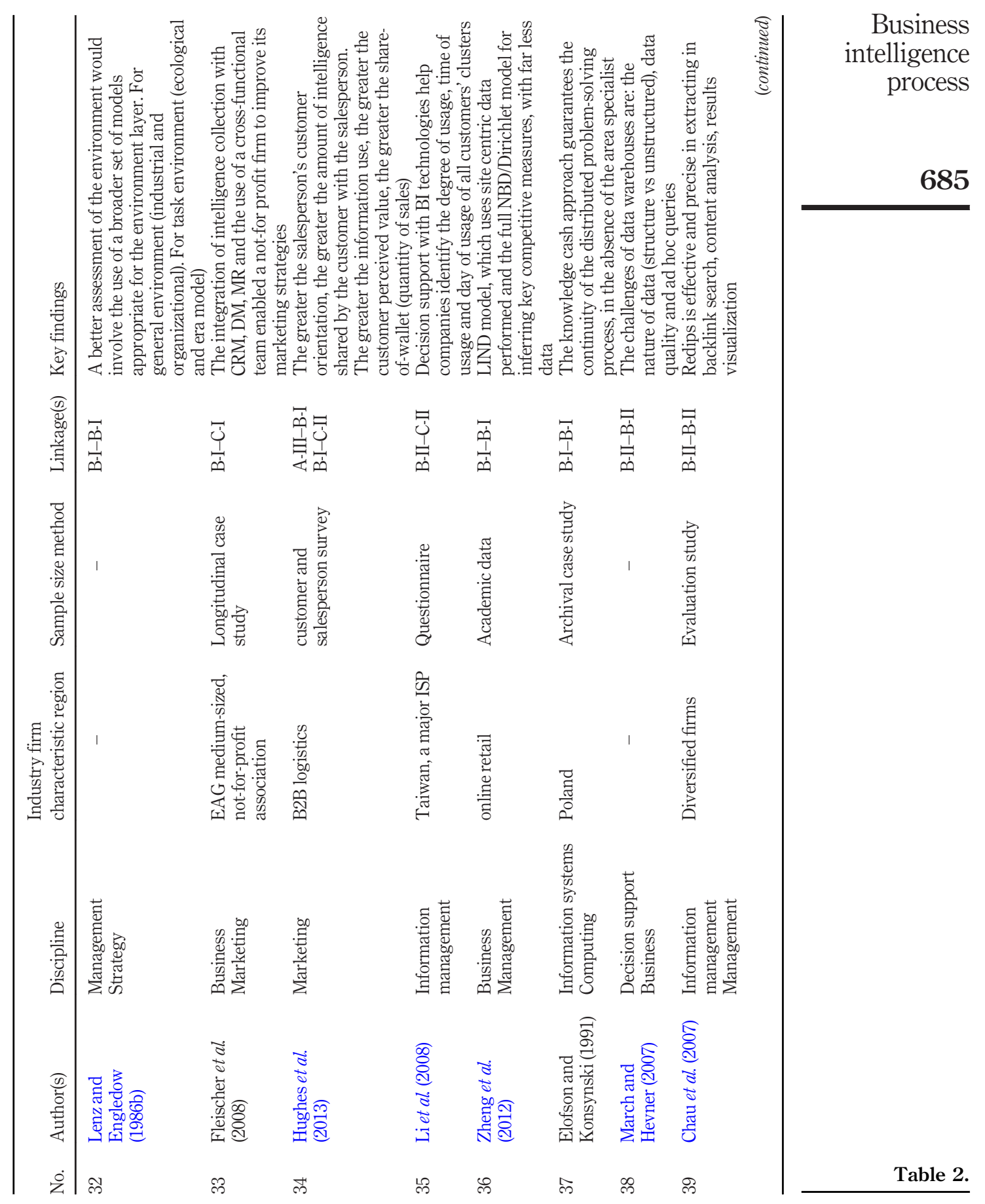


MRR
44,5

Table 2.

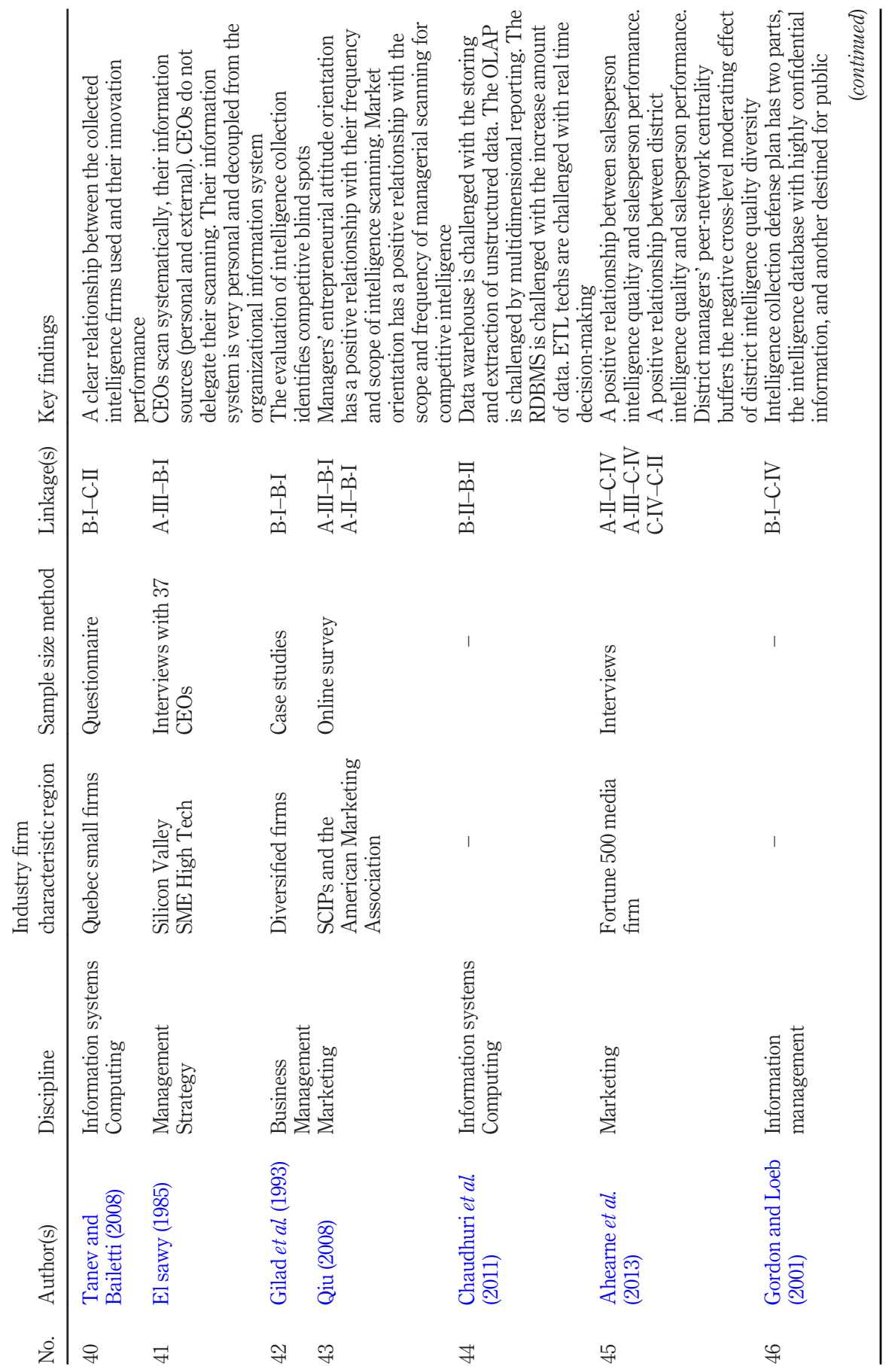




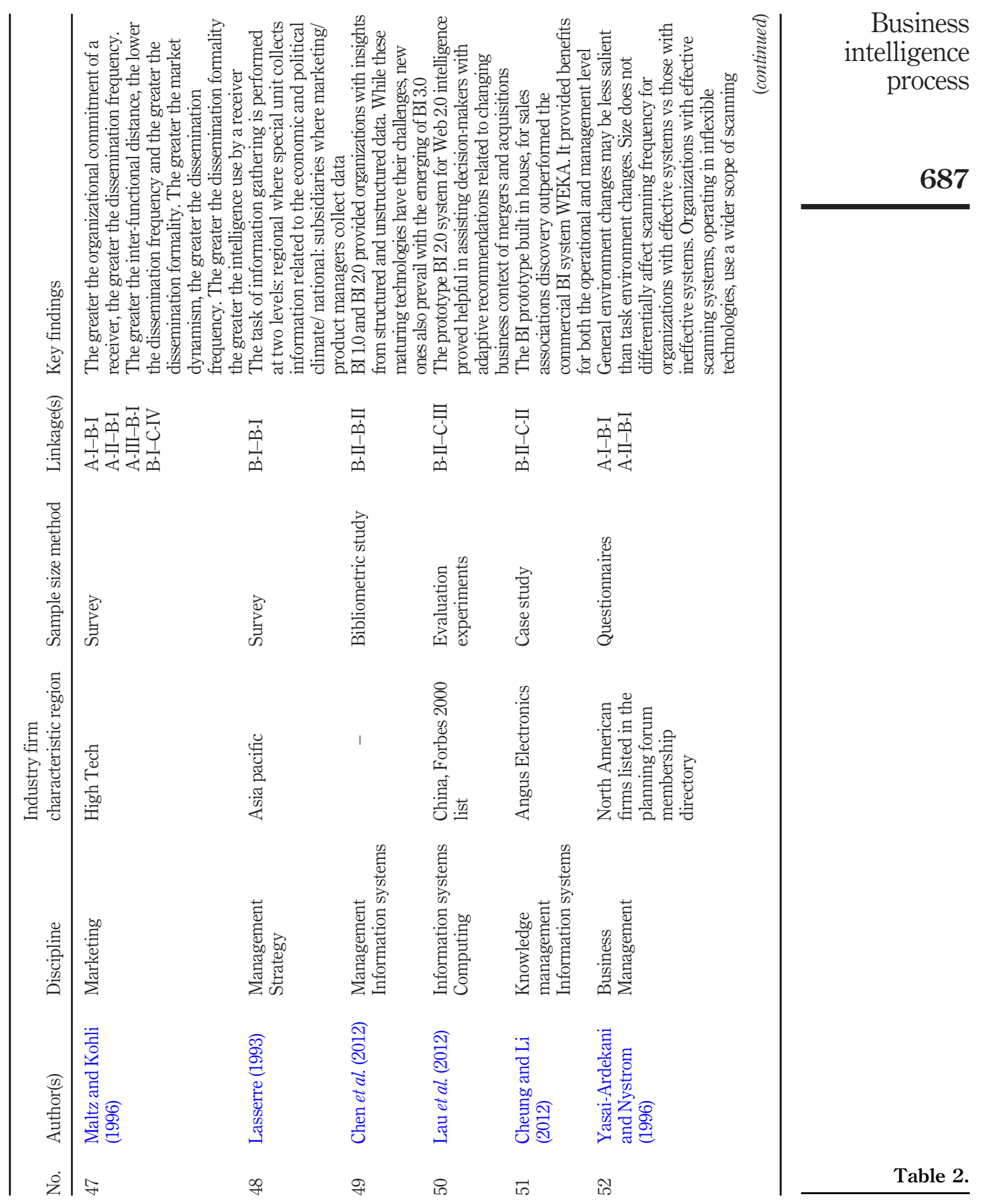




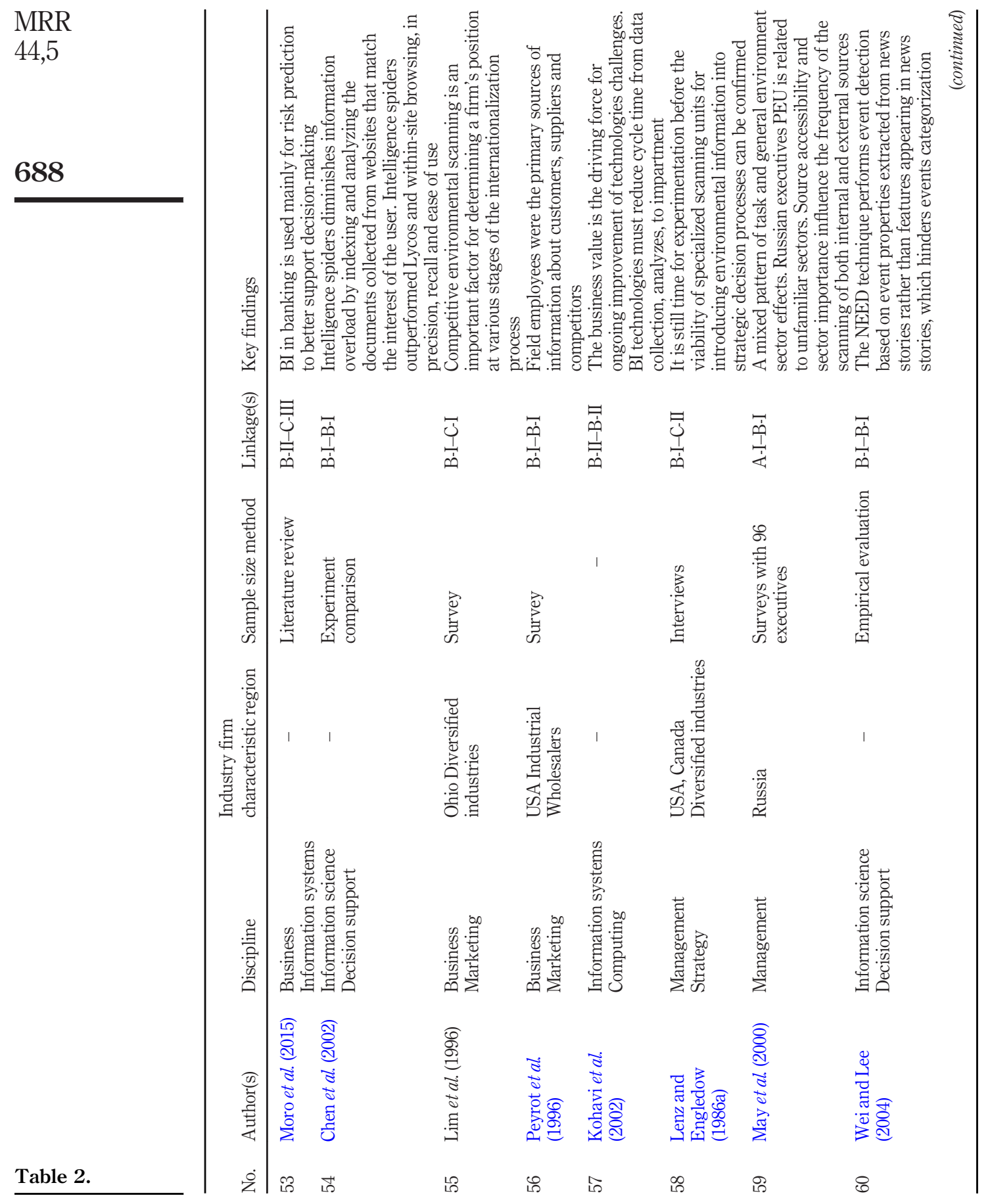







MRR
44,5

690

Table 2.

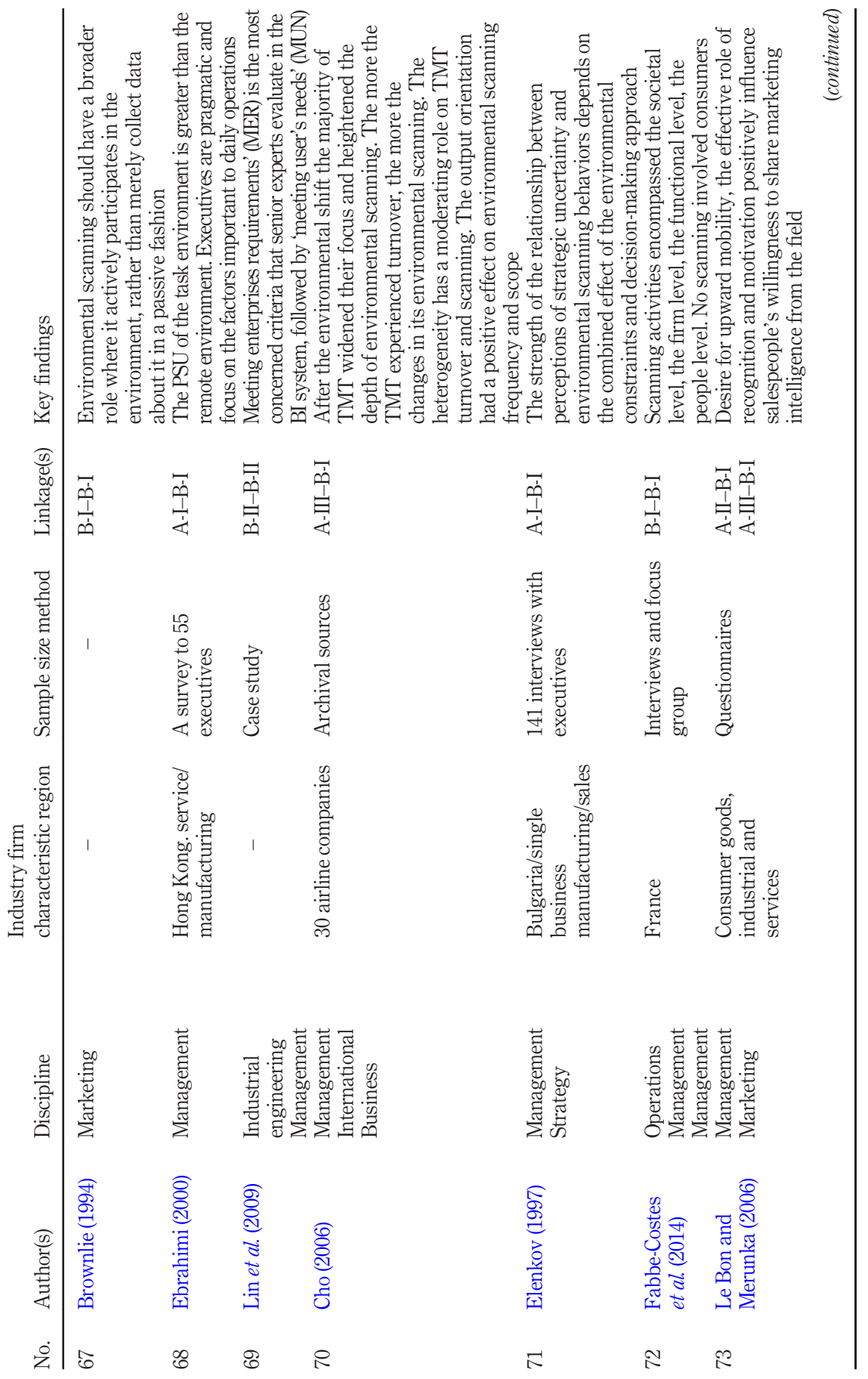




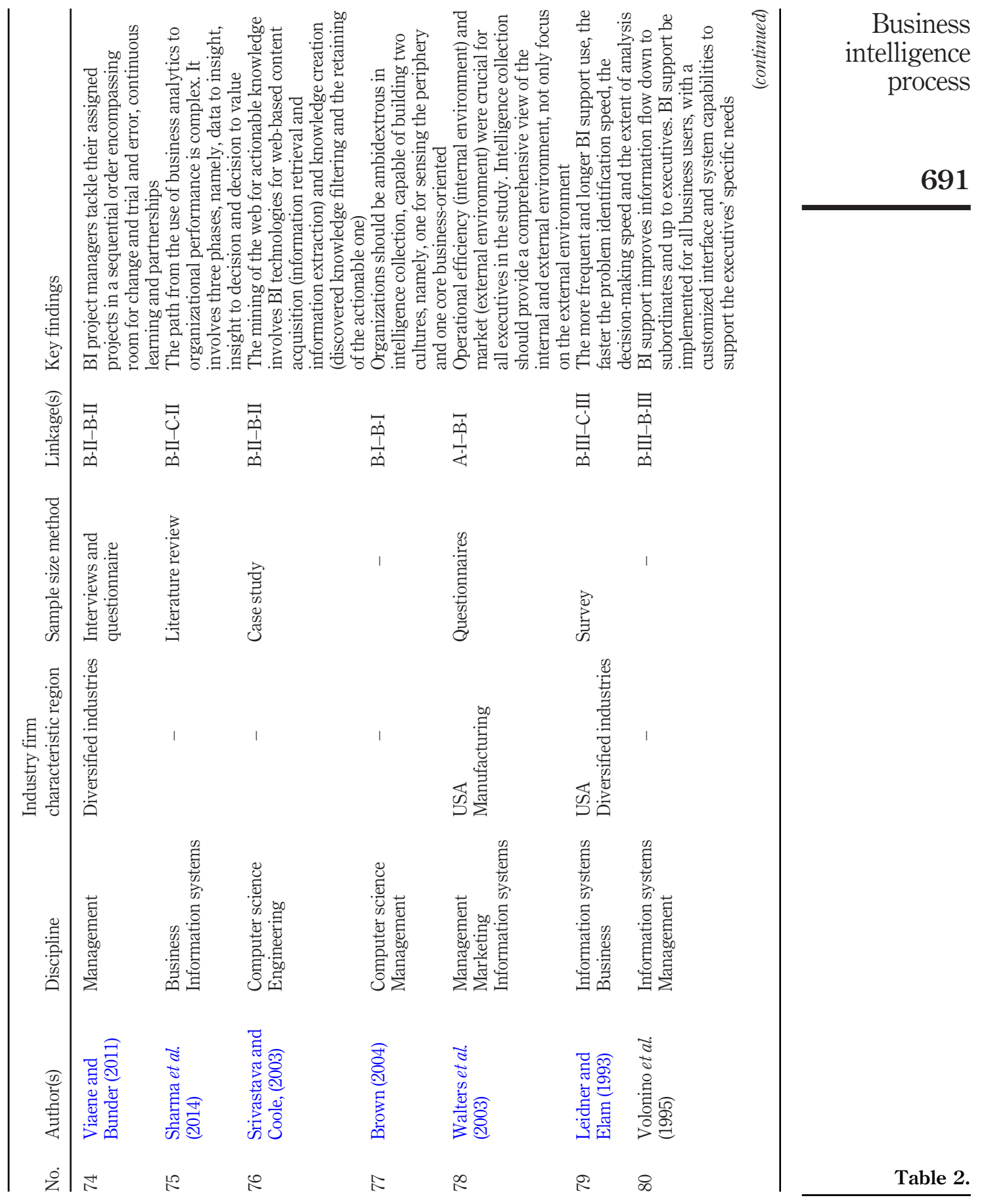


MRR
44,5

692

Table 2.

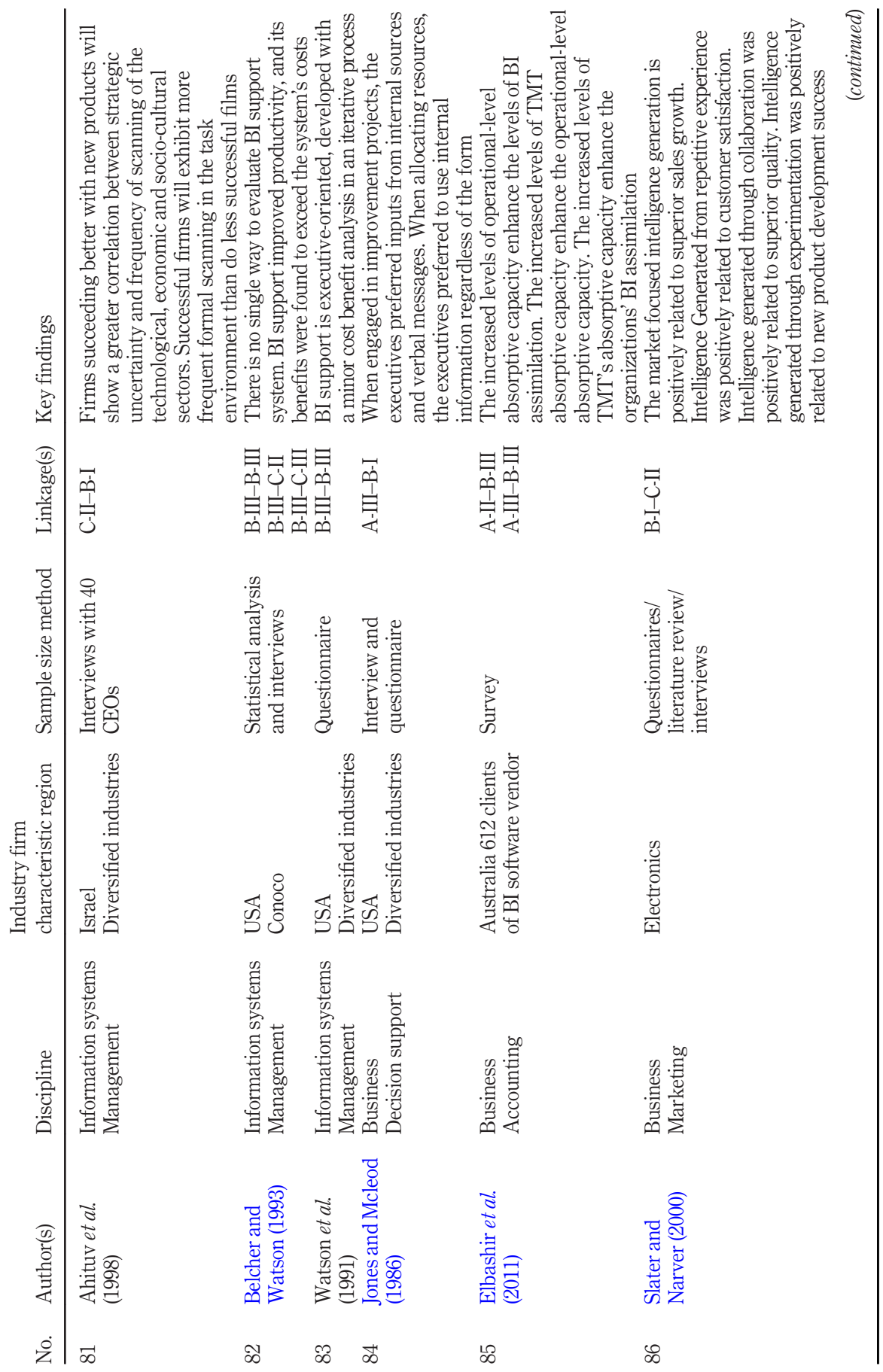




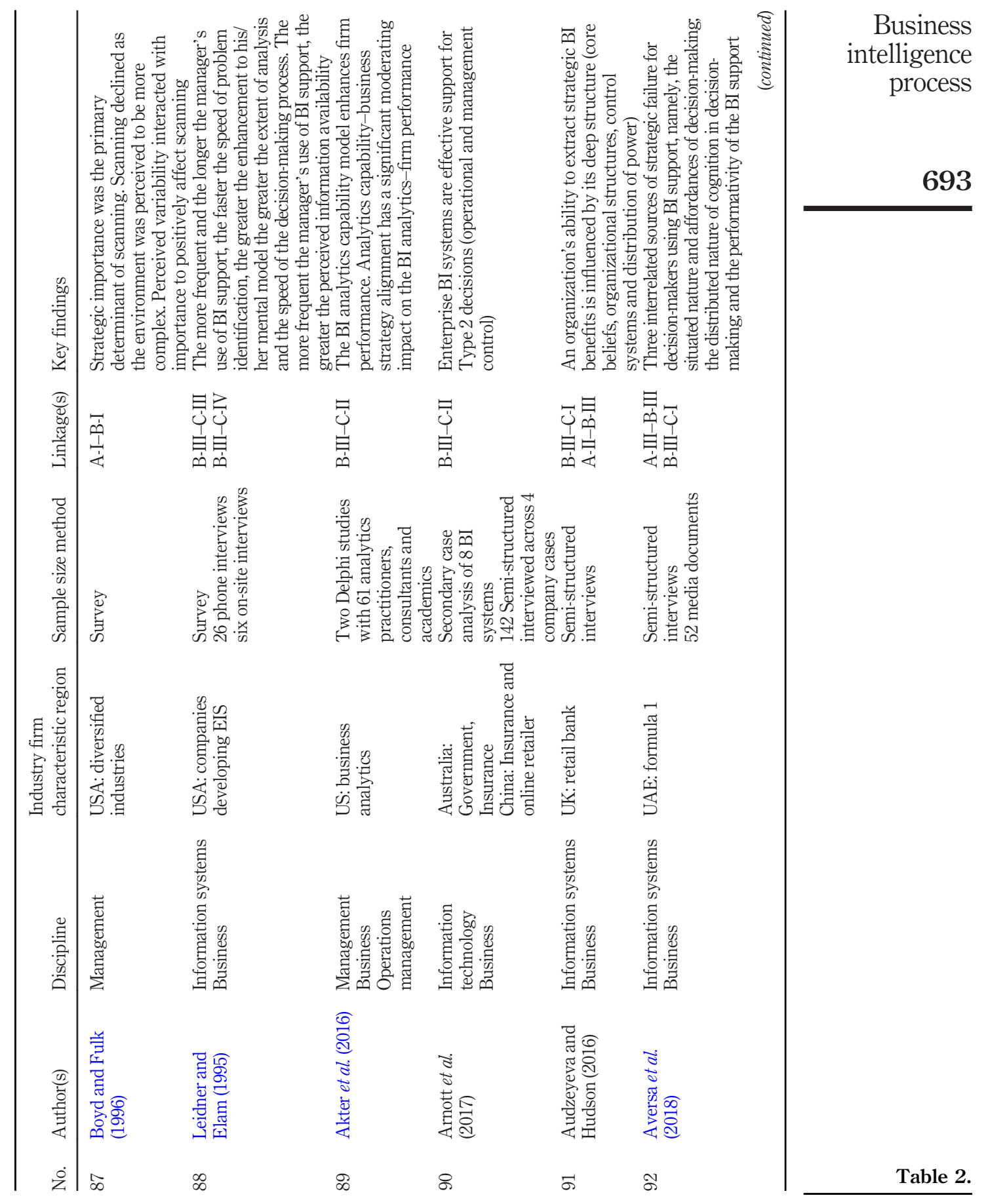


MRR

44,5

694

Table 2.

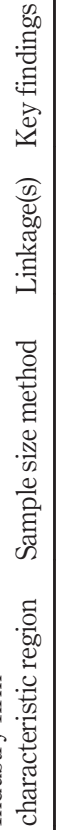

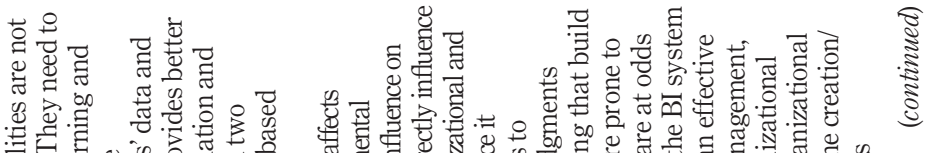

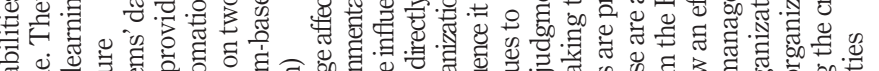

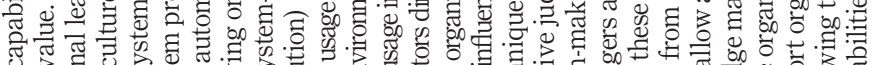

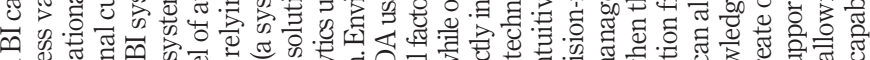

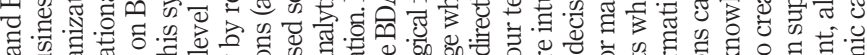

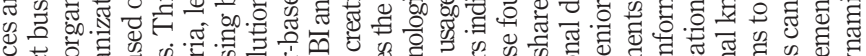

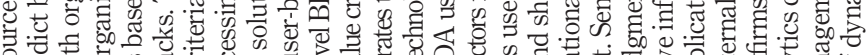

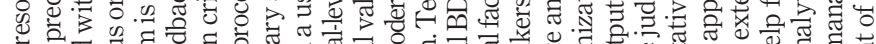

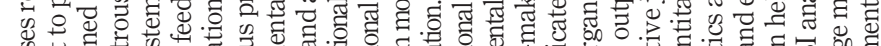

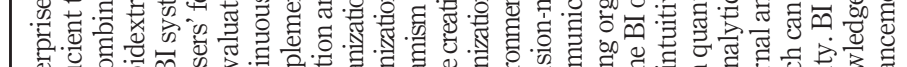

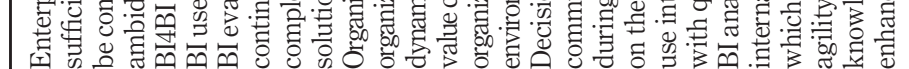

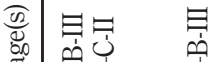
星

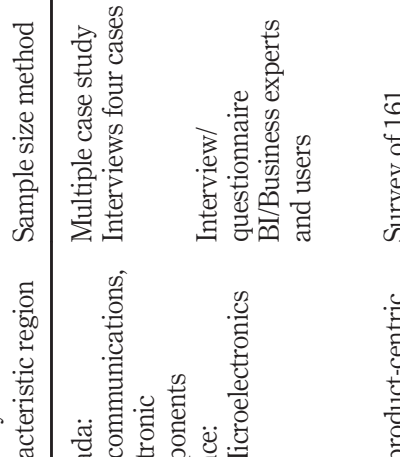

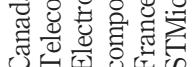

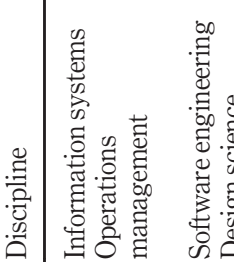

ă

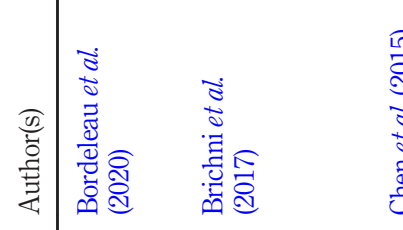

安 ஜ
它寻

当是

$\overrightarrow{6}$

范

䆑

惫

密

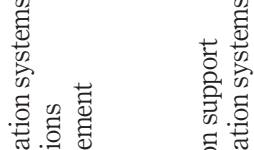

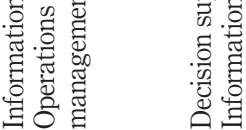

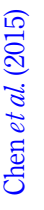

เ8:

몰

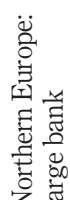

คี

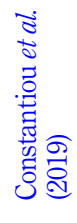

\&
星是是

或

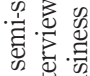

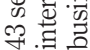

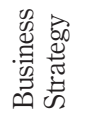

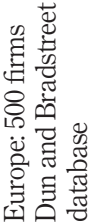

空

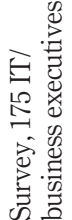

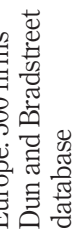




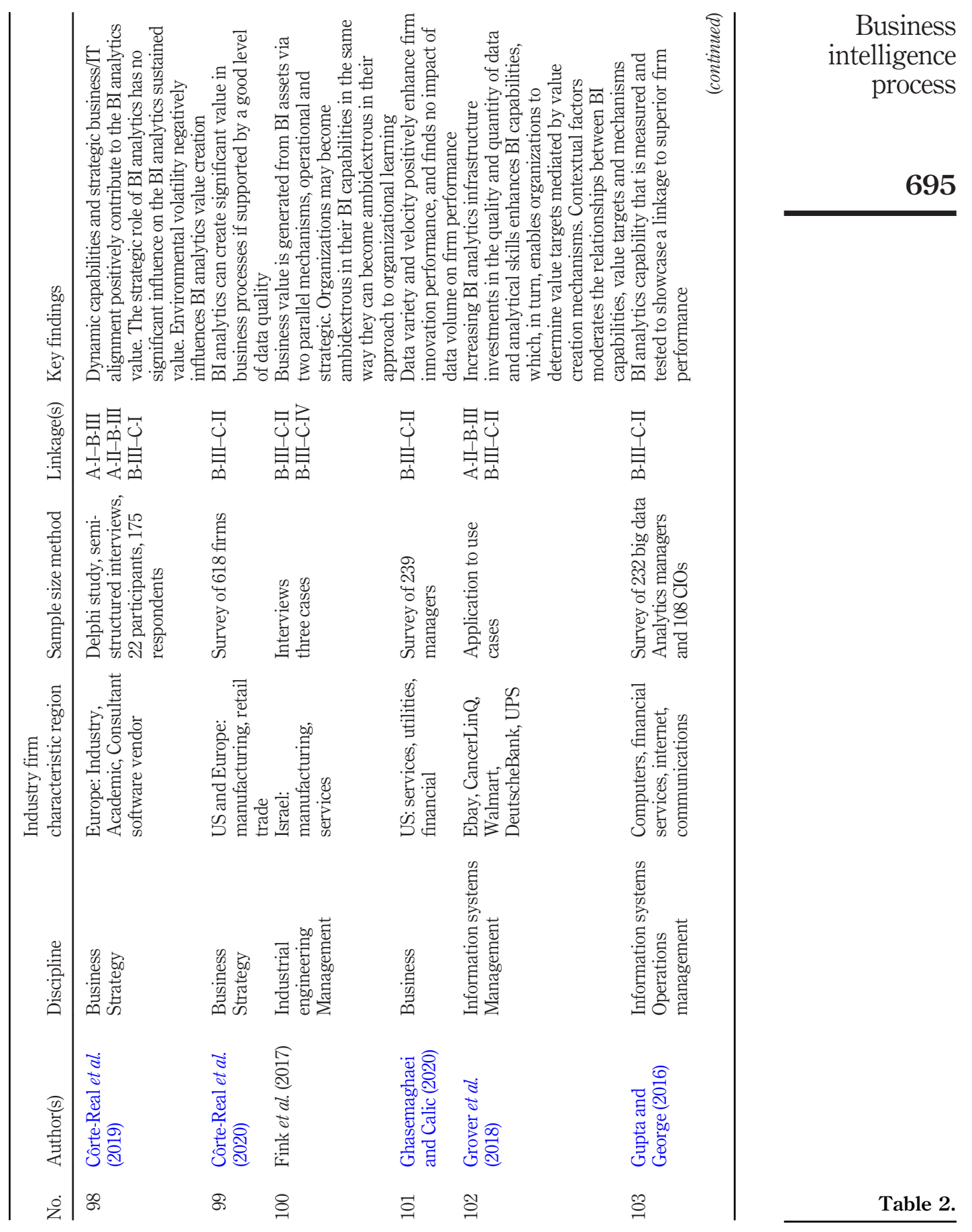


MRR

44,5

696

Table 2.

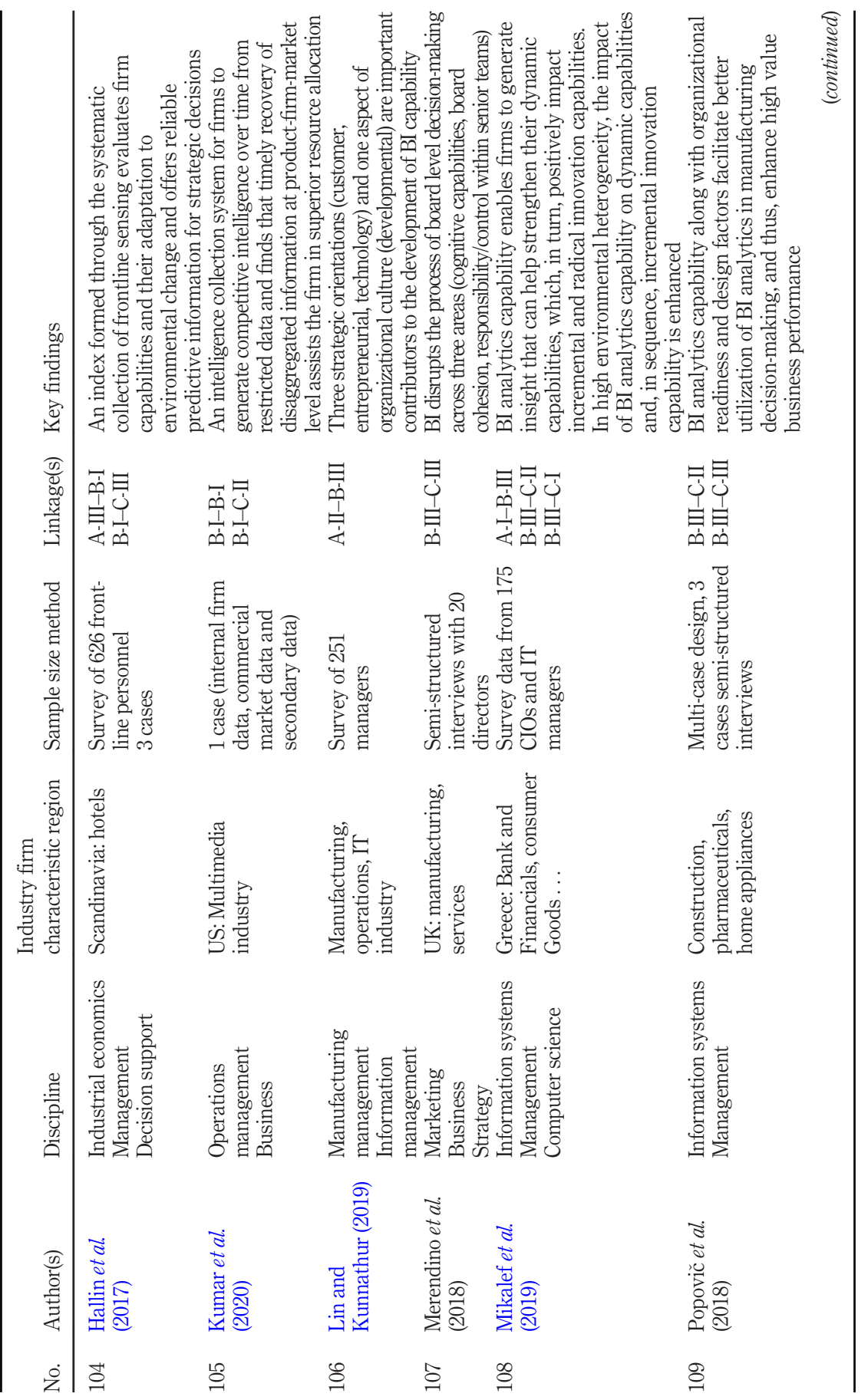




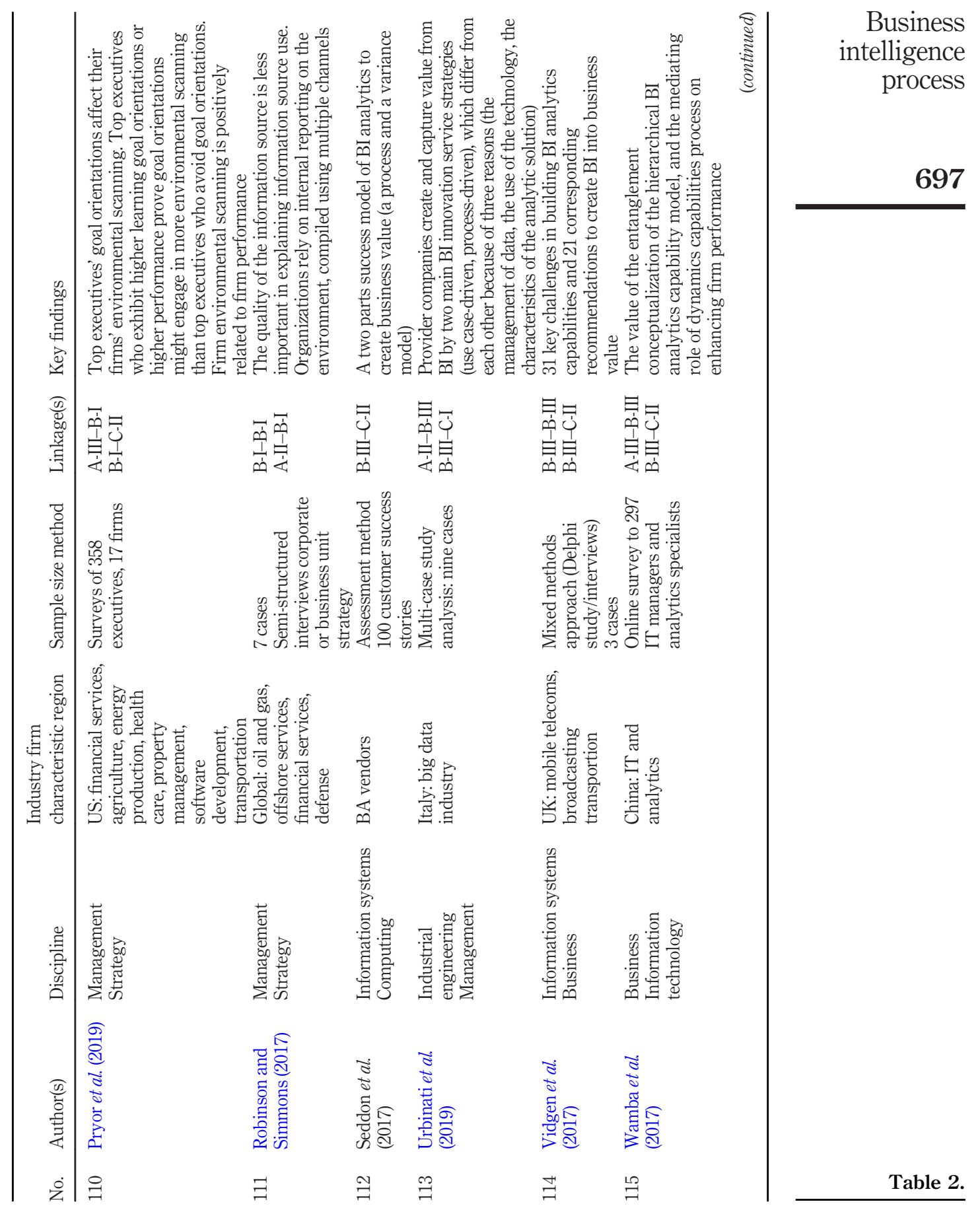


MRR

44,5

698

Table 2.

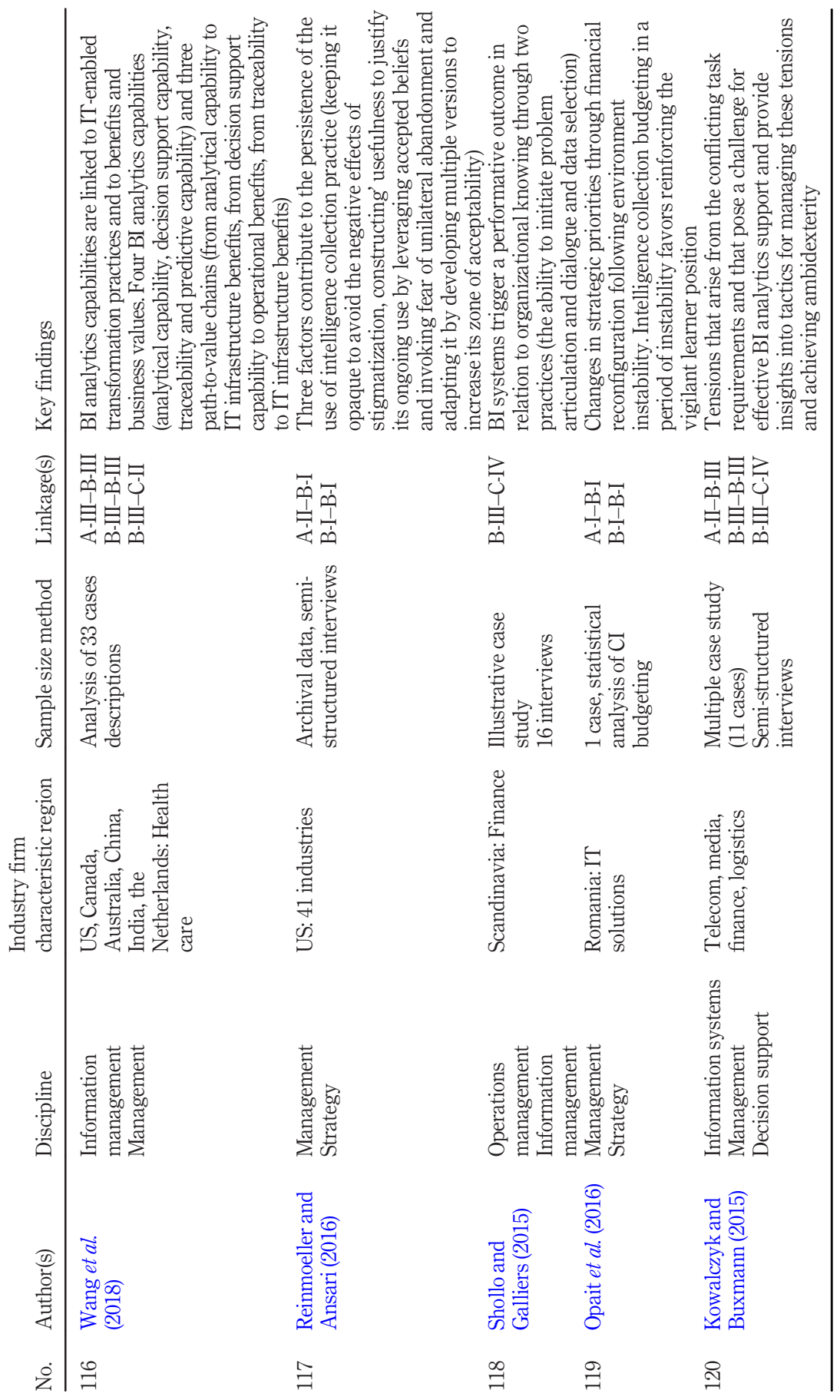


(1) Antecedents. Similar to biological organisms, firms' actions are often constrained by their external environments (Brownlie, 1994). This implies that organizations should constantly monitor their respective environments to ensure the detection of plausible alterations susceptible of jeopardizing their competitive advantage. Their BI processes are, hence, influenced by environmental factors (A-I) such as uncertainty (Hubert and Daft, 1987), complexity (Child, 1972), rate of change (Daft et al., 1988), importance (Aaker, 1983; Pfeffer and Salancik, 1978), culture (Leidner et al., 1999) and competitive pressures (Zhu and Kraemer, 2005). Further influence on the BI process can be attributed to the organizational context (A-II). This may include organizational factors such as size (Yasai-Ardekani and Nystrom, 1996), institutional isomorphism (DiMaggio and Powell, 1983), core technologies (Thompson, 1967), structural flux (Maltz and Kohli, 1996), market orientation (Narver and Slater, 1990) and IT sophistication (Armstrong and Sambamurthy, 1999). Finally, managerial and individual attitudes (A-III) affects the BI process through managerial heterogeneity (Cho, 2006), experience (Thomas et al., 1991), managerial attitude (Qiu, 2008; Pryor et al., 2019), absorptive capacity (Elbashir et al., 2011) and decision roles (Mintzberg, 1973).

(2) BI process. While alterations in the aforementioned antecedents are believed to impact the BI process, characteristics of this latter are also crucial for understanding the different patterns of the BI process literature. At the outset, the intelligence collection phase (B-I) is pictured as the first link between a firm and its environment, whereby it can comprehend the happenings and remain vigilant to changes (Hambrick, 1981; Lönnqvist and Pirttimäki, 2006; Turban et al., 2010). Traditionally, the collection phase was fed through open and human sources. However, with the advent of the internet, it faced the challenge of information overload (Chen et al., 2002). The abundance of data created a lack of executives' attention, and called for a more tailored intelligence transformation phase (B-II) to support managerial action (Fabbe-Costes et al., 2014; Christen et al., 2009). In response, the BI analysts used computerized decision support systems to prepare the requested intelligence for executives (Leidner and Elam, 1993). Such decision aids stimulated, eventually, the design of the executive information system with the purpose of retrieving the information related to internal operations and the business environment (Turban and Schaeffer, 1987; Turban et al., 2010). A further scrutiny of the transformation phase (B-II) reveals that both structured and unstructured data are extracted from operational and external sources, then prepared and loaded into the data warehouse, for a later clustering into Data Marts. This process is usually performed through the extract-transform-load (ETL) application. On the one hand, the data warehouse usually deploys a relational database management system (RDBMS) to store data and rapidly execute queries across a wide range of data. On the other hand, the data warehouse is corroborated by an online analytic processing (OLAP) server in charge of filtering, and drawing thorough analysis (slicing and dicing, drill down...) of the data, which, in turn, is communicated to the user interface (dashboards, spreadsheets. .) that yields the way to the Usage phase (B-III) (Chaudhuri et al., 2011; Sen and Sinha, 2005; Singh et al., 2002). This last phase of the BI process offers the required capability to conduct predictive analysis, streamline intelligence content and ensure an effective practice of the BI process and its alignment across organizational culture, analytical capabilities and the human capital propensity for BI (Holsapple et al., 2014; Viaene and Bunder, 2011; Chaudhuri et al., 2011; Sen and Sinha, 2005; Singh et al., 2002). 
MRR

44,5

700

(3) Outcomes. The BI process was found related to certain outcomes (C): of a strategic order (C-I) such as strategic management process (Hofer, 1978) and managerial representations of competitive advantage (Porac and Thomas, 1990); at a firm performance level (C-II) such as share of wallet (Zeithaml, 1988), customer perceived value (Hughes et al., 2013), product development (Lynn, 1998) and superior sales growth (Slater and Narver, 2000); related to decision-making (C-III) including decision-making speed (Leidner and Elam, 1995), problem identification speed (Leidner and Elam, 1995) and extent of analysis (Miller and Friesen, 1980); and under the umbrella of organizational intelligence (C-IV) encompassing perceived intelligence quality (Popovič et al., 2012), perceived information availability (Leidner and Elam, 1995), intelligence use (Maltz and Kohli, 1996), receiver's trust (Moorman et al., 1992) and insight generation speed (Heinrichs and Lim, 2003).

After plotting the linkages of each study in Table 2, we sought to allow for a visual display of the linkages explored, and the ones overlooked, therefore we juxtaposed the elements of the BI process (BI-II-III), antecedents (AI-II-III) and outcomes (CI-II-III) in a review matrix, exhibited in Figure 1, where rows represent the independent variables, and columns represent the dependent variables, and each coded study (01-120) is allocated into its appropriate linkage cell. Finally, we synthesized and depicted the aforementioned interrelationships in the form of an integrative framework we present in Figure 2. The framework displays three clusters of antecedents (A), namely, environmental factors (A-I), organizational factors (A-II) and managerial and individual attitudes (A-III); three characteristics of the BI process (B), namely, collection (B-I), transformation (B-II), usage (B-III); and four sets of outcomes (C), namely, strategic (C-I), firm performance (C-II), decision-making (C-III) and organizational intelligence (C-IV).

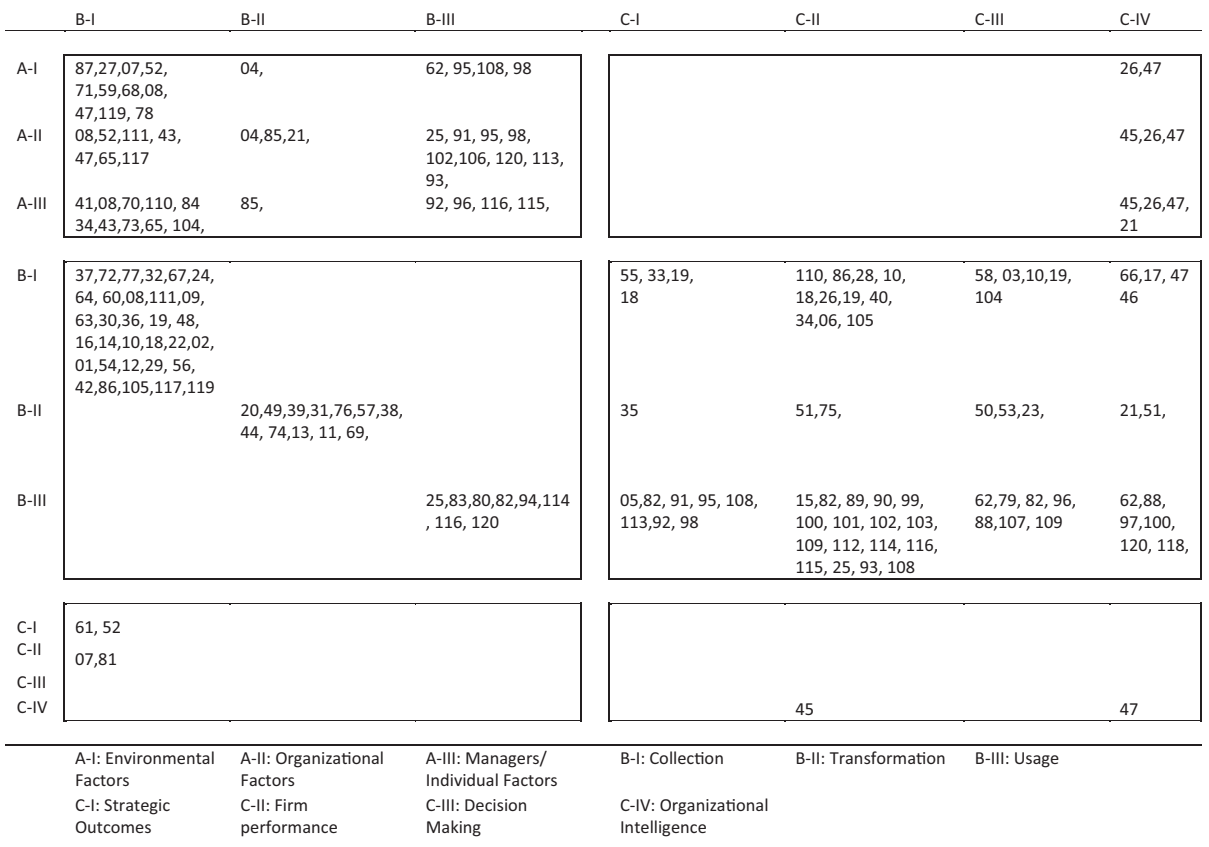

Figure 1. Linkage-exploring review matrix 


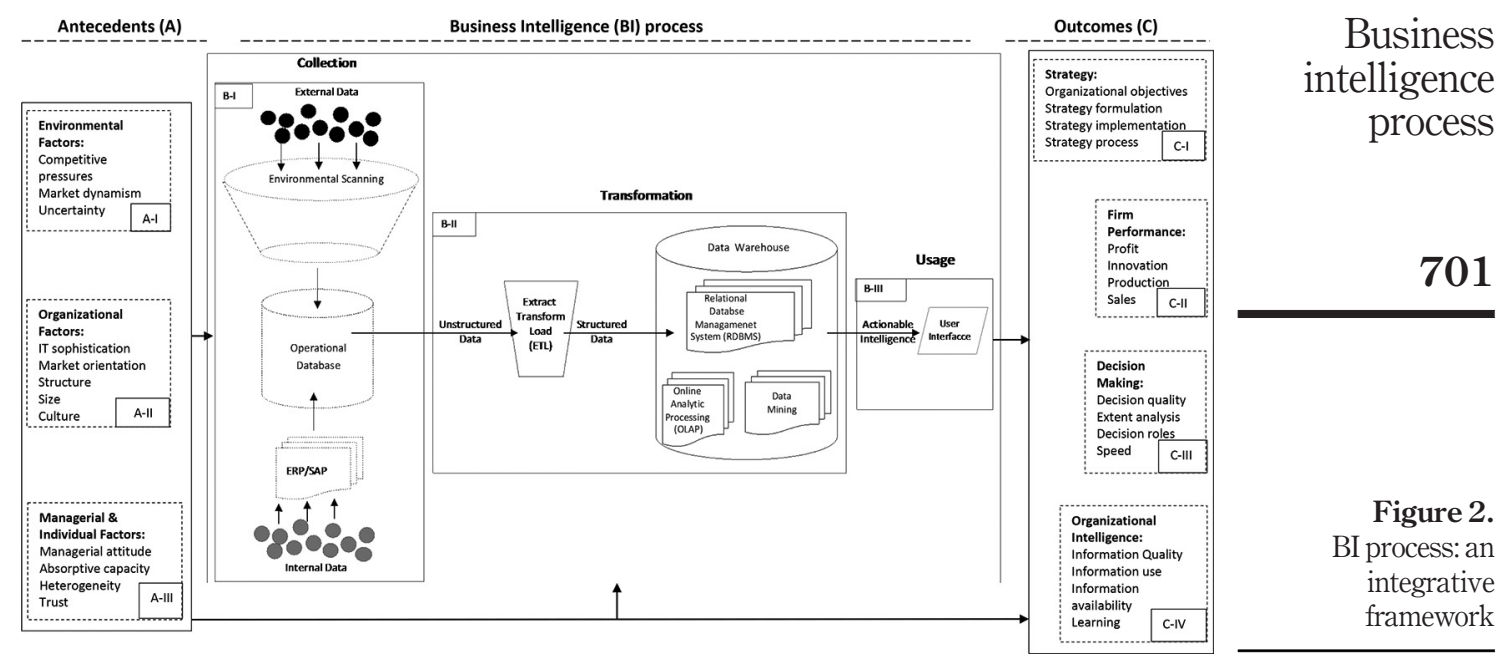

Research within the framework falls into four categories, namely, the first one explores the influence of the antecedents on the BI process (A-I-II-III - B-I-II-III); the second explores the BI phases separately, describing the state of affairs and prescribing optimal processes (B-I-II-III); the third set of studies examines the linkages between the BI process and its ensuing outcomes (B-I-II-III - C-I-II-III-IV); and the fourth set of studies examines the moderating role of antecedents on the relationship between the BI process and outcomes (A-I-II-III - B-I-II-III - C-I-II-III-IV).

\section{Literature synthesis}

Stream 1: the influence of antecedents on the BI process (links A-I-II-III-B-I-II-III)

The environmental influence on the BI process motivated multiple studies that shaped the first cluster of this stream, although the nature of this linkage is still equivocal. This is due to inconsistent views of environmental heterogeneity and uncertainty, and the partial accounts of the BI process. These treatments, rooted in management, bifurcate into two strands. First, a constellation of studies that focus on the frequency and scope of BI collection (Boyd and Fulk, 1996; Daft et al., 1988; Ebrahimi, 2000; Elenkov, 1997; Maltz and Kohli, 1996; May et al., 2000; Sawyerr, 1993). Their findings are at best exploratory and piecemeal as they adopt a "one rule fits all" approach to different environmental layers (e.g. political, customer, direct and remote) let alone country-level contexts (e.g. developed vs developing). By so doing, they overlook the peculiarities of developing economies where other informal pressures and singularities (cultural, institutional and cognitive) moderate the relationship between the environment and BI collection. The second thread of studies examine executives' goal orientations (Pryor et al., 2019), strategic priorities (Opait et al., 2016) quality of information source (El Sawy, 1985; Jones and McLeod, 1986; Robinson and Simmons, 2017), experience and educational background (Cho, 2006), entrepreneurial attitude (Qiu, 2008), intuitive judgments (Constantiou et al., 2019) and boundary spanners' intelligence effort (Le Bon and Merunka, 2006; Mariadoss et al., 2014), customer orientation (Hughes et al., 2013). Unfortunately, these studies overlook to consider the collection activity as a formal unit within the organization, and explore the informal BI collection and source selection of boundary spanners and executives despite previous evidence of their bounded rationality (Cyert and March, 1963). Besides, we still know little about the 
MRR 44,5

upper management's cognitive and managerial characteristics, which implicitly determine their BI collection, not to mention the need to verify, which leadership approach serves best this activity. Credit is given to Elbashir et al. (2011), being the only scholars of this stream who examined the influence of the absorptive capacity of managers on BI assimilation. Similar studies must follow this line to explore the influence of absorptive capacity on the entirety of the BI process. To this date, all we know, in this context, is the positive influence of the absorptive capacity of managers on organizations' BI assimilation (Elbashir et al., 2011). Further, studies examining boundary spanners collecting and gathering of intelligence like their engagement to their desire for upward mobility and recognition. Therefore, boundary spanners' involvement in BI collection is a variable of managerial stimulation, and hence, more studies are needed to examine the moderating effect of management appraisal on the linkage between BI collection and boundary spanners' scope and frequency of BI collection.

The significant focus of management scholars on the environment and the managerial and individual factors as the primary antecedents of the BI process came at the expense of overlooking the organizational factors susceptible of influencing the BI process. Conversely, studies, rooted in marketing and decision support, shed light on the ability of the organizational context to alter the BI process, particularly the collection phase and its linkage to decentralized organizational culture (Babbar and Rai, 1993), size and core technologies (Yasai-Ardekani and Nystrom, 1996), inter-functional distance and structural flux (Maltz and Kohli, 1996), organizational market orientation (Qiu, 2008), resource scarcity (Christen et al., 2009), institutional isomorphism (Ramakrishnan et al., 2012), analytical culture (Holsapple et al., 2014; Popovič et al., 2012); IT infrastructure (Elbashir et al., 2011), organizational culture (Leidner and Elam, 1995, 1999) and organizational beliefs (Reinmoeller and Ansari, 2016). Although harmonious in its uniformity, this line of research was limited to the BI collection phase except for two studies that extended their focus to BI support and its linkage to organizational orientation and culture (Lin and Kunnathur, 2019) and organizational tensions (Kowalczyk and Buxmann, 2015).

\section{Stream 2: the business intelligence process (links B-I-II-III)}

The review of the literature illustrates a shared conceptual meaning, across marketing and management scholars, regarding the nature of BI collection as an activity that seeks to proactively monitor a dynamic environment and that ends once data has been collected (Babbar and Rai, 1993; Bernhardt, 1994; Calof and Wright, 2008; Slater and Narver, 2000). Unfortunately, the literature within this stream was considerably explorative of the BI collection activities and practices (Taylor, 1992; Vedder et al., 1999; Dishman and Calof, 2008; Wright et al., 2009). While some marketing scholars emphasized the use of Bayes' theorem to determine when more collection becomes cost (Michaeli and Simon, 2008), other explored information sources companies use (Fleisher et al., 2008; Lasserre, 1993; Peyrot et al., 1996) or developed indices to evaluate the adaptability of firm capabilities to BI collection of boundary spanners (Hallin et al., 2017) or to collect BI from disaggregated data (Kumar et al., 2020). While a stream of scholars examined trust in BI collection quality (Robinson and Simmons, 2017), others investigated the type and source of the collected intelligence (Peyrot et al., 1996) or the capabilities to decode each type of intelligence be it soft (Lasserre, 1993) or web-based (Fleisher, 2008; Pawar and Sharda, 1997). On the other hand, an apparent discussion within this stream involves the collection approach, i.e. the comprehensive vs the project-based model. A priori, the comprehensive mode seems a better fit to broad strategic decisions, while the ad-hoc approach is more project-oriented. The narrowed focus of the project-based approach is believed to generate more accurate intelligence compared to the holistic model (Prescott and Smith, 1987). Nonetheless, this 
paradox shifts the debate to the culture and the core business of organizations. For some scholars, organizations might choose to participate in the environment rather than passively observing it (Brownlie, 1994). By so doing, the underpinning motive of such an activity swings from BI collection to sense giving (Gioia and Chittipeddi, 1991), from informing to influencing, from a mere passive to proactive BI collection (Brownlie, 1994). Other scholars suggest that ambidexterity arises as a reasonable option whereby the firm can develop two cultures, namely, one for sensing peripheral patterns; the other is core business-oriented (Brown, 2004; O'Reilley and Tushman, 2002; Ghosal and Westney, 1991; Gilad et al., 1993).

Conversely, literature with scaffolding in information systems and decision support, fueled by the desire of bridging the gap between the business user and BI transformation and usage, criticized the firms' focus on collection over analysis despite the challenge of information overload and gave significant attention to testing in-house acquisition techniques of BI collection to curb the exorbitant price of third-party sources by proposing Limited Information NBD/Dirichlet (LIND) models to infer key competitive measures based on site-centric data (Zheng et al., 2012) or two level conditional random fields (CRF) models to extract comparative relation features from entities and words (Xu et al., 2011) or event detection (NEED) applications that perform events detection based on properties extracted from news stories (Wei and Lee, 2004) or proposed 80/20 rule-based models for reduction of cycle time (Kohavi et al., 2002; Liu and Wang, 2008) or suggested data slicing and dicing technologies, which index and analyze documents collected from websites matching users' interest (Chen et al., 2002) or grant rapid access displays of data (Walters et al., 2003). One commonality within this research stream is the evaluation of the proposed tool against the commercial engines (Chen et al., 2002; Zheng et al., 2012; Xu et al., 2011).

The coming of the WEB 2.0, digitization, the internet of things and Big Data further challenged the BI process by technical issues in regard to (a) the time consuming process of transforming and storing structured and unstructured data into the data warehouse, (b) the lack of techniques capable of, simultaneously, alleviating data heterogeneity and integrating slice, dice, roll-up and drill-down dimensions for data evaluation, (c) the multidimensional view of data through OLAP, which needs continuous performance improvement; (d) the rising volume of data, which challenges the capacity of the RDBMSs to query and store data, (e) the pressure on ETL to filter, cluster and integrate current operational data, for real time decision-making support and (d) detect hidden patterns in terabytes of data (Chaudhuri et al., 2011). This ushered most empirical studies in this stream to shift their attention to what Chen et al. (2012) refer to as BI 3.0 or mobile BI and accordingly update BI technologies and develop new applications that can detect patterns in terabytes of data, diminish further information overload, and merge structured with unstructured data (Chen et al., 2012; Srivastava and Cooley, 2003; Chung et al., 2005; Chau et al., 2007; Cheng et al., 2009; Lin et al., 2009) or decipher frameworks for evaluation BI process based on users' feedback (Brichni et al., 2017) or modeling its best practice approach for less challenges (Vidgen et al., 2017; Wang et al., 2018a; 2018b). However, this might not be enough to ensure an effective usage of $\mathrm{BI}$ as this latter hinges on the alignment across organizational culture, analytical capabilities and the human capital propensity for BI (Holsapple et al., 2014; Viaene and Bunder, 2011). No empirical studies have yet to investigate this triadic relationship and its moderating variables for better BI usage.

Stream 3: the influence of the business intelligence process on outcomes (links B-I-II-III-C-III-III-IV)

Drawing from marketing research, scholars explored the influence of BI collection and managerial representation of competitive advantage (Qiu, 2008), managerial belief in 
MRR 44,5 formulating and implementing strategies (Vedder et al., 1999) improvement of marketing strategies (Fleisher et al., 2008). Other scholars suggested that BI collection translates to share of wallet and profit margin (Hughes et al., 2013) and sales performance (Mariadoss et al., 2014), product innovation and competitive pricing strategies (Trim and Lee, 2008), price optimization, expanding product lines and service improvements (Peyrot et al., 1996), superior sales growth, customer satisfaction (Slater and Narver, 2000), innovation (Tanev and Bailetti, 2008) and profitability and revenues increase (Wright et al., 2009). Although these studies might pinpoint to the relationship between BI collection and strategic outcomes, the question of whether or not this step of the BI process contributes to strategy formulation or implementation remains ambiguous.

Furthermore, the available evidence, drawing from management, demonstrates two stocks of research: one that indicates a clear relation between BI support and productivity enhancement, and information distribution cost savings (Belcher and Watson, 1993), price competition (Abramson et al., 2005), firm performance (Akter et al., 2016; Gupta and George, 2016), business value (Côrte-Real et al., 2020; Seddon et al., 2016; Wang et al., 2018a; 2018b), innovation (Ghasemaghaei and Calic, 2020); another that suggests BI support adds value to the organizational intelligence in at least two interrelated ways, namely, workforce learning (Cheung and Li, 2012), information access quality (Popovič et al., 2012), data security (Gordon and Loeb, 2001; McCrohan, 1998; Sheng et al., 2005; Vedder et al., 1999) and intelligence use (Maltz and Kohli, 1996) and organizational knowledge management (Côrte-Real et al., 2017; Shollo and Galliers, 2015).

The research strand, rooted in information systems, was limited to providing benchmarks of their BI support technologies to which they ascribe a linkage to the decisionmaking process. Scholars presented their prototypes and evaluated their success for mergers and acquisitions (Lau et al., 2012), and banking and financial decisions (Moro et al., 2015). Besides, information systems scholars had a penchant for solving tactical issues because of their straightforward evaluation or to scholars' approach to BI, as a set of separate technologies rather than a holistic decisional paradigm. Therefore, their contributions integrate BI technologies such as data warehouse and data mining into BI support and address its ability to improve firm performance indicators. Studies examined and demonstrated the positive impact of BI support on crafting personalized customer strategies (Li et al., 2008), decision-making (Aversa et al., 2018), strengthen innovation capability (Mikalef et al., 2019), business value (Sharma et al., 2014), identify sales ordering patterns (Cheung and Li, 2012), business model insight (Heinrichs and Lim, 2003). Research, herein, seems obsessed with solving tactical issues because of their straightforward evaluation or to scholars' approach to BI as a set of separate technologies rather than a holistic decisional paradigm.

Studies rooted in decision support empirically examined the linkage between BI support and the speed of problem identification, decision-making speed and the extent of analysis (Leidner et al., 1999; Leidner and Elam, 1993; Leidner and Elam, 1995; Belcher and Watson, 1993; Arnott et al., 2017). Still little is known about how BI collection influences decisionmaking. While it is true that explorative studies reveal the utility of BI collection for organizational decision-making (Ghosal and Westney, 1991; Vedder et al., 1999), no empirical evidence has yet examined this belief. The outcome of BI collection on decisionmaking might be, as well negative than positive, at least for competitor analysis blind spots in the case of capacity expansion, new business entry and acquisition (Zajac and Bazerman, 1991). One might keep wonder about the contexts and the extent to which BI can bring value to the decision-making if scholars' attention does not shift from explorative, inductive 
studies to more cross functional longitudinal ones to further delve into the relation between $\mathrm{BI}$ and the decision-making process.

Stream 4: the moderating effects of antecedents on the relationship between the business intelligence process and outcomes (links A-I-II-III - B-I-II-III-C-I-II-III-IV)

This stream of research is threefold, namely, research at the individual level, organizational level and environment level. At the individual level, scholars, with scaffolding in marketing research, investigated the moderating role of boundary spanners adaptive skills on BI collection sales performance outcomes (Hughes et al., 2013; Mariadoss et al., 2014; Ahearne et al., 2013), the moderating role of the relationship between intelligence officers and strategists on boosting product innovation and generating competitive pricing strategies (Trim and Lee, 2008), the moderating effect of the relationship between district managers centrality and district BI quality diversity on salespersons' performance (Ahearne et al., 2013). Unfortunately, studies rooted in management and information systems or decision support overlooked the moderating role of antecedents at the individual level on the relationship between $\mathrm{BI}$ process and outcomes.

At the organizational level, management scholars explored the moderating role of the alignment between business strategy and IT on the relationship between BI usage and business value (Côrte-Real et al., 2019; Urbinati et al., 2019), the moderating role of the relationship between the alignment of business strategy and BI analytics on BI usage and firm performance (Akter et al., 2016), the moderating role of deep organizational structure on the relationship between BI usage and strategy outcomes (Audzeyeva and Hudson, 2015), the moderating role of organizational learning and ambidextrous organizational culture on the relationship between BI usage and business value (Bordeleau et al., 2020) and BI usage and organizational learning (Fink et al., 2016) and the mediating role of dynamic capabilities on the relationship of BI usage and firm performance (Wamba et al., 2017). In like fashion, marketing scholars investigated the moderating effects of the relationships between organizational antecedents such as structural flux and perceived intelligence quality on BI usage (Maltz and Kohli, 1996), the curvilinear relationship between organizational size and BI use, as well as between marketing departments size and BI usage (Peyrot et al., 2002). On the other hand, decision support scholars shed light on the moderating role of decision-making culture on the relation between the BI content quality and the BI usage (Popovic et al., 2012), the moderating role of the relationship between organizational readiness and design factors on the relationship between BI usage and business value (Popovič et al., 2012) and the moderating role of the information system BI infrastructure investment on the relationship between BI usage and value targets (Grover et al., 2018).

At the environmental level, marketing scholars showcased the moderating role of the relationship between perceived competitiveness of the environment and the perceived value of BI quality on BI usage and organizational outcomes (Maltz and Kohli, 1996; Peyrot et al., 2002). On the other hand, one study, rooted in information systems, explored the moderating role of the environment dynamism on the influence of the BI usage on value creation (Chen et al., 2015).

\section{Future research}

35 years of BI process research seemed fragmented and scattered around similar areas, with scant initiatives to weave strands of lookalike contributions into one unifying paradigm. Research spawned a considerable number of articles partly prescriptive, partly explorative, revealing discrepancies between theory and practice across the BI process, antecedents and outcomes. Figure 3 displays the covered and underexplored areas in each of the 


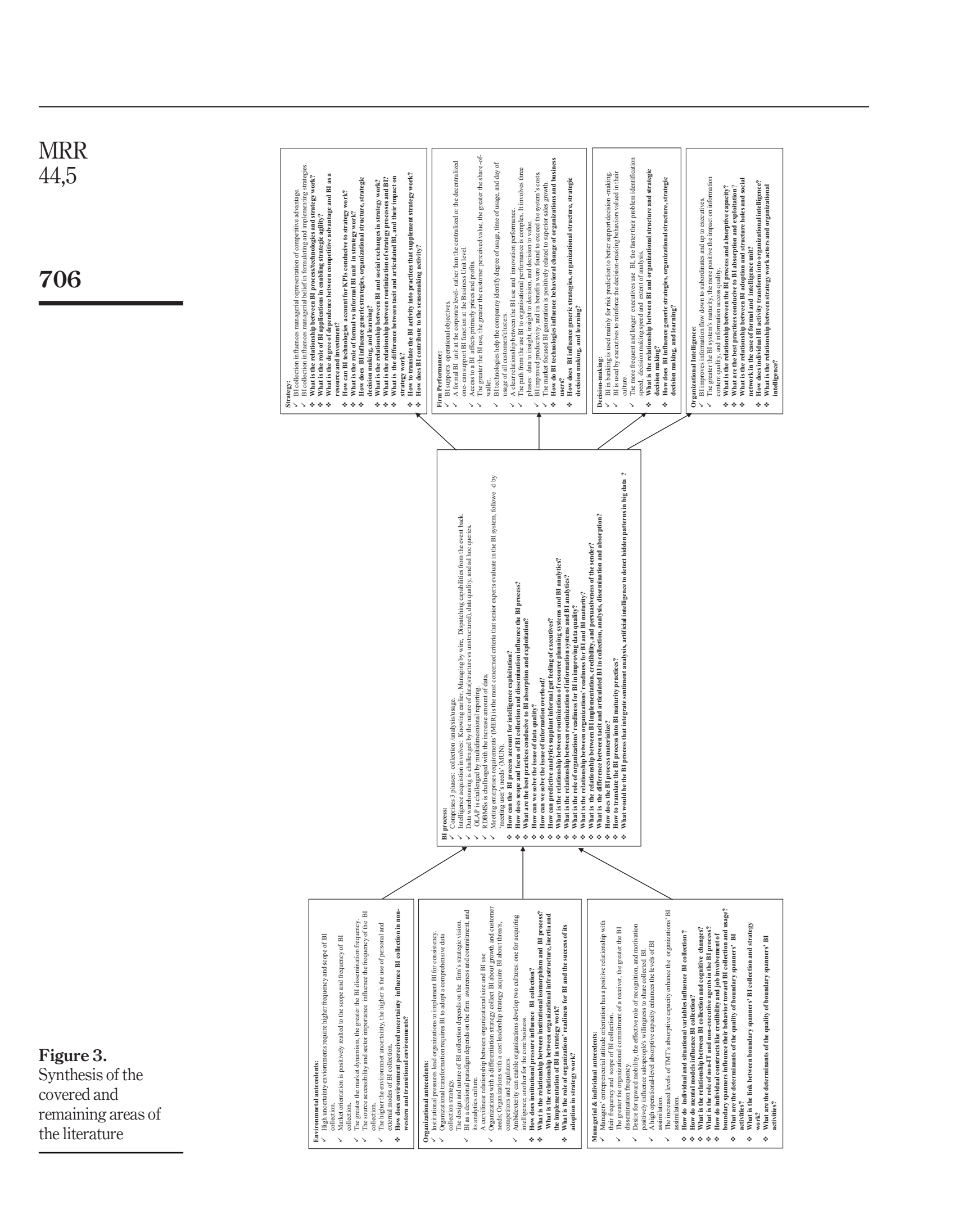


aforementioned streams. Antecedents exploring studies focused on the supply side of the market to formulate viable strategies for an existing industry. These contributions unanimously adopted an outside in perspective, examining the external environmental influence on the frequency and mode of BI collection. They adopted the same structuralist approach to different business environments and neglected the influence of cultural factors and institutional pressures on the BI process. Another limitation of this stream is the exclusiveness of collection activity to executives, rather than the organization as a whole, following a topdown approach in an apparent discontinuity from the literature on bounded rationality that grant executives limited capacity to fathom the dynamism of the environment.

The significant focus on the environment as the primary antecedent of BI collection marginalized discussions on organizational factors susceptible of influencing the BI process. For instance, the ramifications of one single event on the BI use of multinational corporations in different settings. In this vein, managerial heterogeneity seems a potential frontier for research through which scholars shall compare heterogeneous teams to homogeneous groups of executives' vis-a-vis their uncertainty perception and use of the BI process. Additionally, researchers still need to investigate, which structure represents an environment ripe for effective BI use: organic or mechanistic structure. Similarly, the causation link between strategic orientation and BI process is still vague, despite some studies suggest a one-way association from strategic orientation to BI collection. Moreover, contrary to the trend line of recommendation positing the BI process at the outset of the decision-making or the strategic management process, the authors of the article at hand personally encountered situations, in monopolistic economies, where the BI process was regarded more as legitimacy tools that solidify an already taken decisional or strategic choice. As a corollary, it might be crucial to incorporate the singularity of the decision-making process in developing countries, when hypothesizing coming empirical studies. Another trend line across studies examining BI use is the focus on the receiver's trust in regard to the intelligence sender. Nonetheless, this latter's willingness to share intelligence was treated as a given, while it is far from being the case. Particularly, in developing countries where information is shared among individuals pertaining to the same interest groups. It becomes, hence, evident to account for the sender's trust and influence on the BI dissemination and use, in future research.

In addition, cognitive factors of managers and boundary spanners were rarely on the scholars' agenda. After all, the environmental uncertainty is a matter of interpretation, which, in turn, is framed by intrinsic factors rooted in the person's background. More studies, in this respect, should incorporate elements such as age, gender and personality traits. Moreover, the rationale behind decision-makers' BI collection behavior still appears ambiguous, for there seems to be no evidence regarding the value it adds to their mental models. Another overlooked matter by scholars, caught in an everlasting development of new ways of codifying structured and unstructured data, is the ability of the BI process to acquire and communicate tacit knowledge. Another gap worth mentioning is the scarcity of studies comparing BI practices of multinational corporations in the western world to emerging countries, in a world where anything might happen any second, where new technologies disrupt the status quo of businesses, economies and political regimes. The Covid-19 epidemic, political upheavals or data privacy issues present an opportunity for researchers to examine the linkage between the BI process and strategic agility let alone employees' and organizations' privacy and readiness for disruption.

Finally, a myriad of research methods was adopted by scholars, to delve into issues related to the BI process phases ranging from bibliometric studies, surveys and case studies. Some were conceptual papers, whereas others field tested their hypotheses or settled for laboratory experiments. Except for qualitative exploration examining linkage between 
MRR 44,5
BI transformation to decision-making success, benchmarking data mining or data warehousing applications against commercial products marked most BI transformation studies, let alone the quantitative exploratory and conceptual articles representing a common trend across studies tackling BI collection. The absence of comparative studies urges researchers to invest time and money probing differences across industries, not in an exploratory superficial manner, but more as a longitudinal thorough analysis depicting whether or not the industry type is a contributing factor to the BI process. Longitudinal studies were, surprisingly, absent, notwithstanding their presence in multiple scholars' future directions. Another advantage longitudinal studies shall have is related to the evaluation of prototypes and technologies in an accurate manner, encompassing the residual value of such applications on the organizational learning. Longitudinal studies might also enable scholars to tap into cognitive changes prior and after BI collection and usage and track front line managers intelligence use as they assume high level positions. With that said, studies shall alter to a more dynamic view of the environment capable of capturing all the various interactions among its constantly shifting elements.

\section{Practical implications}

Nowadays, confidential strategies and tactics are swiftly replicated; the sustainability of the competitive advantage is no longer a result of a secret recipe. Managers shall recognize that room for intuition is shrinking as the need for a rational predictability is rising. Therefore, it seems wiser and beneficial for managers to tear down their walls, and engage in double loop learning with scholars, should they want a better real time decision-making and strategic agility. This review carries some implications for practitioners and particularly the role they ought to play should they seek actionable intelligence as an outcome of the BI process. Across the studies this review examined, managerial reluctance to open their intelligence practices to close examination was omnipresent. Although their apathy is understandable, due to their frustration regarding the lack of measurability of intelligence constructs, managers manifestly share a significant amount of responsibility in turning out explorative and descriptive studies partly due to their defensive managerial participation. Interestingly, managers would rather keep an ineffective BI unit confidential than open it for assessment in fear of competition or bad publicity. Therefore, this review highlights the value open participation of managers in longitudinal studies could bring to the BI research and by extent the new open intelligence culture across their organizations where knowledge is overt, intelligence is participative, not selective and where double loop learning alongside scholars is continuous. Their commitment to open participation and longitudinal studies will help generate new research that better integrates the $\mathrm{BI}$ process within its context and fosters new measures for intelligence performance.

\section{Conclusion}

Although far from completeness, this systematic review strived to synthesize the BI process body of knowledge via an integrative process framework that pinpoints to areas of redundancies and research gaps where scholars' attention should be directed. It is hoped that this article will encourage researchers to change perspective and adopt a more comprehensive view of the BI process aimed at contributing to its organizational context and focus its attention on the interrelationships across the BI process, antecedents and outcomes. Drawing from Levy and Ellis (2006) and Webster and Watson (2002), we sought comprehensiveness from four databases and quality from the ABS ranking list. Therefore, this paper excludes conference papers and book chapters. A caveat regarding the 26 keywords of this study is worth mentioning, as there might surely be some articles that the query strings failed to retrieve; let alone in-press- publications, not yet available when 
the database search took place. Notwithstanding, a backward search of references allowed the verification of this review's comprehensiveness, gauged near completion when no new concepts were identified in the literature set (Webster and Watson, 2002). However, the material upon which this scrutiny is based epitomizes an open invitation for other researchers, to compare and test whether or not the results herein stand up to close examination. After all, this is the ultimate way to expand and enrich the body of knowledge probing BI process research.

\section{Business intelligence process}

709

\section{References}

Aaker, D.A. (1983), "Organizing a strategic information scanning system”, California Management Review, Vol. 25 No. 2, pp. 76-83.

Abramson, C., Currim, I.S. and Sarin, R. (2005), "An experimental investigation of the impact of information on competitive decision making", Management Science, Vol. 51 No. 2, pp. $195-207$.

Ahearne, M., Lam, S.K., Hayati, B. and Kraus, F. (2013), "Intrafunctional competitive intelligence and sales performance: a social network perspective”, Journal of Marketing, Vol. 77 No. 5, pp. 37-56.

Akter, S., Wamba, S.F., Gunasekaran, A., Dubey, R. and Childe, S.J. (2016), "How to improve firm performance using big data analytics capability and business strategy alignment?", International Journal of Production Economics, Vol. 182, pp. 113-131, doi: 10.1016/j.jpe.2016.08.018.

Armstrong, C.P. and Sambamurthy, V. (1999), "Information technology assimilation in firms: the influence of senior leadership and IT infrastructures", Information Systems Research, Vol. 10 No. 4, pp. 304-327.

Arnott, D. and Pervan, G. (2005), “A critical analysis of decision support systems research”, Journal of Information Technology, Vol. 20 No. 2, pp. 67-87, doi: 10.1057/palgrave.jit.2000035.

Arnott, D. and Pervan, G. (2014), "A critical analysis of decision support systems research revisited: the rise of design science", Journal of Information Technology, Vol. 29 No. 4, pp. 269-293, doi: $10.1057 /$ jit.2014.16.

Arnott, D., Lizama, F. and Song, Y. (2017), "Patterns of business intelligence systems use in organizations", Decision Support Systems, Vol. 97, pp. 58-68.

Audzeyeva, A. and Hudson, R. (2015), "How to get the most from a business intelligence application during the post implementation phase? Deep structure transformation at a U.K. retail bank", European Journal of Information Systems, Vol. 25 No. 1, pp. 1-18, doi: 10.1057/ejis.2014.44.

Aversa, P., Cabantous, L. and Haefliger, S. (2018), "When decision support systems fail: insights for strategic information systems from Formula 1", The Journal of Strategic Information Systems, Vol. 27 No. 3, pp. 221-236, doi: 10.1016/j.jsis.2018.03.002.

Babbar, S. and Rai, A. (1993), "Competitive intelligence for international business", Long Range Planning, Vol. 26 No. 3, pp. 103-113.

Bandara, W., Furtmueller, E., Beekhuyzen, J., Gorbacheva, E. and Miskon, S. (2015), “Achieving rigour in literature reviews: insights from qualitative data analysis and tool-support", Communications of the Association for Information Systems, Vol. 34 No. 8, pp. 154-204.

Belcher, L. and Watson, H. (1993), “Assessing the value of Conoco's EIS”, MIS Quarterly, Vol. 17 No. 3, pp. 239-269.

Bernhardt, D.C. (1994), "I want it fast, factual, actionable-tailoring competitive intelligence to executives' needs", Long Range Planning, Vol. 27 No. 1, pp. 12-24.

Bingham, C.B. and Eisenhardt, K.M. (2011), "Rational heuristics: the 'simple rules' that strategists learn from process experience”, Strategic Management Journal, Vol. 1464, pp. 1-43, doi: 10.1002/smj.

Bordeleau, F.E., Mosconi, E. and de Santa-Eulalia, L.A. (2020), "Business intelligence and analytics value creation in industry 4.0: a multiple case study in manufacturing medium enterprises", Production Planning and Control, Vol. 31 Nos 2/3, pp. 173-185, doi: 10.1080/09537287.2019.1631458. 
MRR 44,5

Boyd, B. and Fulk, J. (1996), "Executive scanning and perceived uncertainty: a multidimensional model", Journal of Management, Vol. 22 No. 1, pp. 1-21.

Brichni, M., Dupuy-Chessa, S., Gzara, L., Mandran, N. and Jeannet, C. (2017), "BI4BI: a continuous evaluation system for business intelligence systems", Expert Systems with Applications, Vol. 76, pp. 97-112.

Brown, J.S. (2004), "Minding and mining the periphery", Long Range Planning, Vol. 37 No. 2, pp. 143-151, doi: 10.1016/j.lrp.2004.01.001.

Brownlie, D. (1994), “Organizing for environmental scanning: orthodoxies and reformations”, Journal of Marketing Management, Vol. 10 No. 8, pp. 703-723.

Calof, J.L. and Wright, S. (2008), "Competitive intelligence: a practitioner, academic and interdisciplinary perspective", European Journal of Marketing, Vol. 42 Nos 7/8, pp. 717-730.

Chau, M., Shiu, B., Chan, I. and Chen, H. (2007), "Redips: backlink search and analysis on the web for business intelligence analysis", Journal of the American Society for Information Science and Technology, Vol. 14 No. 4, pp. 90-103.

Chaudhuri, S., Dayal, U. and Narasayya, V. (2011), "An overview of business intelligence technology", Communications of the ACM, Vol. 54 No. 8, pp. 88-98.

Chen, D.Q., Preston, D.S. and Swink, M. (2015), "How the use of big data analytics affects value creation in supply chain management", Journal of Management Information Systems, Vol. 32 No. 4, pp. 4-39, doi: 10.1080/07421222.2015.1138364.

Chen, H., Chau, M. and Zeng, D. (2002), "CI spider: a tool for competitive intelligence on the web”, Decision Support Systems, Vol. 34 No. 1, pp. 1-17.

Chen, H., Chiang, R. and Storey, V. (2012), "Business intelligence and analytics: from big data to big impact”, MIS Quarterly, Vol. 36, pp. 1165-1188.

Cheng, H., Lu, Y.-C. and Sheu, C. (2009), "An ontology-based business intelligence application in a financial knowledge management system”, Expert Systems with Applications, Vol. 36 No. 2, pp. 3614-3622.

Cheung, C. and Li, F. (2012), "A quantitative correlation coefficient mining method for business intelligence in small and medium enterprises of trading business", Expert Systems with Applications, Vol. 39 No. 7, pp. 6279-6291.

Child, J. (1972), "Organizational structure, environment and performance: the role of strategic choice", Sociology, Vol. 6 No. 1, pp. 1-22.

Cho, T.S. (2006), "The effects of executive turnover on top management team's environmental scanning behavior after an environmental change", Journal of Business Research, Vol. 59 Nos 10/11, pp. 1142-1150.

Christen, M., Boulding, W. and Staelin, R. (2009), "Optimal market intelligence strategy when management attention is scarce", Management Science, Vol. 55 No. 4, doi: 10.1287/mnsc.1080.0988.

Chung, W., Chen, H. and Nunamaker, J.F.J. (2005), "A visual framework for knowledge discovery on the web: an empirical study of business intelligence exploration", Journal of Management Information Systems, Vol. 21 No. 4, pp. 57-84.

Constantiou, I., Shollo, A. and Vendelø, M.T. (2019), "Mobilizing intuitive judgement during organizational decision making: when business intelligence is not the only thing that matters", Decision Support Systems, Vol. 121, pp. 51-61, doi: 10.1016/j.dss.2019.04.004.

Côrte-Real, N., Oliveira, T. and Ruivo, P. (2017), "Assessing business value of big data analytics in European firms", Journal of Business Research, Vol. 70, pp. 379-390, doi: 10.1016/j. jbusres.2016.08.011.

Côrte-Real, N., Ruivo, P. and Oliveira, T. (2020), "Leveraging internet of things and big data analytics initiatives in European and American firms: is data quality a way to extract business value?", Information and Management, Vol. 57 No. 1, p. 103141, doi: 10.1016/j. im.2019.01.003. 
Côrte-Real, N., Ruivo, P., Oliveira, T. and Popovič, A. (2019), "Unlocking the drivers of big data analytics value in firms", Journal of Business Research, Vol. 97, pp. 160-173, doi: 10.1016/j. jbusres.2018.12.072.

Culnan, M.J. (1978), "An analysis of the information usage patterns of academics and practitioners in the computer field: a citation analysis of a national conference proceedings", Information Processing and Management, Vol. 14 No. 6, pp. 395-404, doi: 10.1016/0306-4573(78)90004-3.

Cyert, R.M. and March, J.G. (1963), A Behavioral Theory of the Firm, Prentice-H, Englewood Cliffs, NJ.

Daft, R.R.L.R., Sormunen, J. and Parks, D. (1988), "Chief executive scanning, environmental characteristics, and company performance: an empirical study", Strategic Management Journal, Vol. 9 No. 2, pp. 123-139.

Davenport, T. and Paul Barth, R.B. (2012), "How 'big data' is different", MIT Sloan Management Review, Vol. 54 No. 1, pp. 43-46, available at: http://sloanreview.mit.edu/article/how-big-data-isdifferent/\#article-authors

Davenport, T.H., Harris, J.G., De Long, D.W. and Jacobson, A.L. (2001), "Data to knowledge to results", California Management Review, Vol. 43 No. 2, p. 117, available at: http://search.ebscohost.com/ login.aspx?direct $=$ true $\& \mathrm{db}=$ buh $\& \mathrm{AN}=4372997 \&$ site $=$ ehost-live

DiMaggio, P.J. and Powell, W. (1983), "The iron cage revisited" institutional isomorphism and collective rationality in organizational fields", American Sociological Review, Vol. 48 No. 2, pp. 147-160.

Dishman, P.L. and Calof, J.L. (2008), "Competitive intelligence: a multiphasic precedent to marketing strategy”, European Journal of Marketing, Vol. 42 Nos 7/8, pp. 766-785.

Ebrahimi, B.P.B. (2000), "Environmental complexity, importance, variability and scanning behavior of Hong Kong executives", Journal of Business Research, Vol. 49 No. 1, pp. 67-77.

Ekbia, H., Mattioli, M., Kouper, I., Arave, G., Ghazinejad, A., Bowman, T., Suri, V.R., Tsou, A., Weingart, S. and Sugimoto, C.R. (2015), "Big data, bigger dilemmas: a critical review", Journal of the Association for Information Science and Technology, Vol. 66 No. 8, pp. 1523-1545, doi: $10.1002 /$ asi.

El Sawy, O.A. (1985), "Personal information systems for strategic scanning in turbulent environments: can the CEO go on-line?”, MIS Quarterly, Vol. 9 No. 1, pp. 53-60.

Elbashir, M., Collier, P. and Sutton, S. (2011), "The role of organizational absorptive capacity in strategic use of business intelligence to support integrated management control systems", The Accounting Review, Vol. 86 No. 1, pp. 155-184.

Elenkov, D. (1997), "Strategic uncertainty and environmental scanning: the case for institutional influences on scanning behavior", Strategic Management Journal, Vol. 18 No. 4, pp. 287-302.

Eom, S. and Kim, E. (2006), “A survey of decision support system applications (1995-2001)”, Journal of the Operational Research Society, Vol. 57 No. 11, pp. 1264-1278, doi: 10.1057/palgrave.jors.2602140.

Fabbe-Costes, N., Christine, R., Margaret, T. and Taylor, A. (2014), "Sustainable supply chains: a framework for environmental scanning practices", International Journal of Operations and Production Management, Vol. 34 No. 5, pp. 664-694.

Fink, L., Yogev, N. and Even, A. (2016), "Business intelligence and organizational learning: an empirical investigation of value creation processes", Information and Management, Vol. 54 No. 1, pp. 38-56, doi: 10.1016/j.im.2016.03.009.

Fischer, T., Dietz, J. and Antonakis, J. (2016), "Leadership process models: a review and synthesis", Journal of Management, Vol. 43 No. 6, pp. 1726-1753, doi: 10.1177/0149206316682830.

Fleisher, C.S. (2008), "Using open source data in developing competitive and marketing intelligence", European Journal of Marketing, Vol. 42 Nos 7/8, pp. 852-866.

Fleisher, C.S., Wright, S. and Allard, H.T. (2008), "The role of insight teams in integrating diverse marketing information management techniques", European Journal of Marketing, Vol. 42 Nos 7/8, pp. 836-851. 
MRR 44,5

Ghasemaghaei, M. and Calic, G. (2020), "Assessing the impact of big data on firm innovation performance: big data is not always better data", Journal of Business Research, Vol. 108, pp. 147-162, doi: 10.1016/j.jbusres.2019.09.062.

Ghosal, S. and Westney, D.E. (1991), "Organizing competitor analysis systems”, Strategic Management Journal, Vol. 12, pp. 17-31.

Ghoshal, S. and Kim, S.K.S.K. (1986), "Building effective intelligence systems for competitive advantage", Sloan Management Review, Vol. 28 No. 1, pp. 49-58.

Gilad, B., Gordon, G., Sudit, E., Gordon, G. and Sudit, E. (1993), "Identifying gaps and blind spots in competitive intelligence", Long Range Planning, Vol. 26 No. 6, pp. 107-113, doi: 10.1016/00246301(93)90212-X.

Gioia, D. and Chittipeddi, K. (1991), "Sense making and sense giving in strategic change initiation", Strategic Management Journal, Vol. 12 No. 6, pp. 433-444.

Gordon, L.A. and Loeb, M.P. (2001), "Using information security as a response to competitor analaysis systems", Communications of the ACM, Vol. 44 No. 9, pp. 70-75.

Grover, V., Chiang, R.H.L., Liang, T.P. and Zhang, D. (2018), "Creating strategic business value from big data analytics: a research framework", Journal of Management Information Systems, Vol. 35 No. 2, pp. 388-423, doi: 10.1080/07421222.2018.1451951.

Gupta, M. and George, J.F. (2016), "Toward the development of a big data analytics capability", Information and Management, Vol. 53 No. 8, pp. 1049-1064, doi: 10.1016/j.im.2016.07.004.

Haeckel, S.H. (2004), "Peripheral vision: Sensing and acting on weak signals making meaning out of apparent noise: the need for a new managerial framework", Long Range Planning, Vol. 37 No. 2 , pp. 181-189.

Hallin, C.A., Andersen, T.J. and Tveterås, S. (2017), "Harnessing the frontline employee sensing of capabilities for decision support”, Decision Support Systems, Vol. 97, pp. 104-112, doi: 10.1016/j. dss.2017.03.009.

Hambrick, D.C. (1981), "Environment, strategy, and power within top management teams", Administrative Science Quarterly, Vol. 26 No. 2, pp. 253-276.

Hart, C. (1998), Doing a Literature Review: Releasing the Social Science Research Imagination, Sage, London.

Heinrichs, J.H. and Lim, J. (2003), "Integrating web-based data mining tools with business models for knowledge management", Decision Support Systems, Vol. 35 No. 1, pp. 103-112.

Hofer, C.W. (1978), Strategic Management: A Casebook in Policy and Planning, West Publishing, St. Paul, MN.

Holsapple, C., Lee-Post, A. and Pakath, R. (2014), “A unified foundation for business analytics”, Decision Support Systems, Vol. 64, pp. 130-141.

Huber, G.P. and Daft, R.L. (1987), "The information environment of organizations", Handbook of Organizational Communication: An Interdisciplinary Perspective, Sage Publi, Newbury Park, CA, pp. 130-164.

Hughes, D., Le Bon, J. and Rapp, A. (2013), “Gaining and leveraging customer-based competitive intelligence: the pivotal role of social capital and salesperson adaptive selling skills", Journal of the Academy of Marketing Science, Vol. 41 No. 1, pp. 91-110.

Hutzschenreuter, T. and Kleindienst, I. (2006), "Strategy-process research: what have we learned and what is still to be explored", Journal of Management, Vol. 32 No. 5, pp. 673-720, doi: 10.1177/ 0149206306291485.

Jones, J.W. and McLeod, R.J. (1986), "The structure of executive information systems: an exploratory analysis", Decision Sciences, Vol. 17 No. 2, pp. 220-249.

Jourdan, Z., Rainer, R.K. and Marshall, T.E. (2008), "Business intelligence: an analysis of the literature", Information Systems Management, Vol. 25 No. 2, pp. 121-131, doi: 10.1080/10580530801941512.

Kohavi, R., Rothleder, N. and Simoudis, E. (2002), "Emerging trends in business analytics", Communications of the ACM, Vol. 45 No. 8, pp. 45-48. 
Kowalczyk, M. and Buxmann, P. (2015), "An ambidextrous perspective on business intelligence and analytics support in decision processes: insights from a multiple case study", Decision Support Systems, Vol. 80, pp. 1-13, doi: 10.1016/j.dss.2015.08.010.

Kumar, V., Saboo, A.R., Agarwal, A. and Kumar, B. (2020), "Generating competitive intelligence with limited information: a case of the multimedia industry", Production and Operations Management, Vol. 29 No. 1, pp. 192-213, doi: 10.1111/poms.13095.

Lasserre, P. (1993), "Gathering and interpreting strategic intelligence in Asia Pacific", Long Range Planning, Vol. 26 No. 3, pp. 56-66.

Lau, R.Y., Liao, S.S.Y., Wong, K. and Chiu, D.K.W. (2012), "Web 2.0 environmental scanning and adaptive decision support for business mergers and acquisitions”, MIS Quarterly, Vol. 36 No. 2, pp. 1239-1268.

Le Bon, J. and Merunka, D. (2006), "The impact of individual and managerial factors on salespeople's contribution to marketing intelligence activities", International Journal of Research in Marketing, Vol. 23 No. 4, pp. 395-408.

Leidner, D. and Elam, J. (1993), "Executive information systems: their impact on executive decision making", Journal of Management Information Systems, Vol. 10 No. 3, pp. 139-155.

Leidner, D. and Elam, J. (1995), "The impact of executive information systems on organizational design, intelligence, and decision making", Organization Science, Vol. 6 No. 6, pp. 645-665.

Leidner, D.E., Carlsson, S., Elam, J. and Corrales, M. (1999), "Mexican and Swedish managers' perceptions of the impact of EIS on organizational intelligence, decision making, and structure", Decision Sciences, Vol. 30 No. 3, pp. 632-658.

Lenz, R.T. and Engledow, J.L. (1986a), "Environmental analysis units and strategic decision-making: a field study of selected 'leading-edge'corporations", Strategic Management Journal, Vol. 7 No. 1, pp. 69-89.

Lenz, R.T. and Engledow, J.L. (1986b), "Environmental analysis: the applicability of current theory", Strategic Management Journal, Vol. 7 No. 4, pp. 329-346.

Levy, Y. and Ellis, T. (2006), "A systems approach to conduct an effective literature review in support of information systems research", Informing Science Journal, Vol. 9, pp. 181-212, doi: 10.1109/IEEM.2012.6837801

Li, S.T.S., Shue, L.L.Y.L. and Lee, S.F.S. (2008), "Business intelligence approach to supporting strategymaking of ISP service management", Expert Systems with Applications, Vol. 35 No. 3, pp. 739-754.

Lin, C. and Kunnathur, A. (2019), "Strategic orientations, developmental culture, and big data capability", Journal of Business Research, Vol. 105, pp. 49-60, doi: 10.1016/j.jbusres.2019.07.016.

Lin, Y.-H., Tsai, K.-M., Shiang, W.-J., Kuo, T.-C. and Tsai, C.-H. (2009), "Research on using ANP to establish a performance assessment model for business intelligence systems", Expert Systems with Applications, Vol. 36 No. 2, pp. 4135-4146.

Liu, C.-H. and Wang, C. (2008), "Forecast competitor service strategy with service taxonomy and CI data", European Journal of Marketing, Vol. 428 No. 7, pp. 746-765.

Lönnqvist, A. and Pirttimäki, V. (2006), "Measurement of business intelligence: forthcoming in information systems management", Information Systems Management, Vol. 23 No. 1.

Loock, M. and Hinnen, G. (2015), "Heuristics in organizations: a review and a research agenda", Journal of Business Research, Vol. 68 No. 9, pp. 2027-2036, doi: 10.1016/j.jbusres.2015.02.016.

McCrohan, K.F. (1998), "Competitive intelligence: preparing for the information war”, Long Range Planning, Vol. 31 No. 4, pp. 586-593.

Maltz, E. and Kohli, A.A.K. (1996), "Market intelligence dissemination across functional boundaries", Journal of Marketing Research, Vol. 33 No. 1, pp. 47-47.

March, S. and Hevner, A. (2007), "Integrated decision support systems: a data warehousing perspective", Decision Support Systems, Vol. 43 No. 3, pp. 1031-1043. 
MRR 44,5

Mariadoss, B.J., Milewicz, C., Lee, S. and Sahaym, A. (2014), "Salesperson competitive intelligence and performance: the role of product knowledge and sales force automation usage", Industrial Marketing Management, Vol. 43 No. 1, pp. 136-145.

May, R., Stewart, W. and Sweo, R. (2000), “Environmental scanning behavior in a transitional economy: evidence from Russia", Academy of Management Journal, Vol. 43, pp. 403-427.

Michaeli, R. and Simon, L. (2008), "An illustration of Bayes' theorem and its use as a decision-making aid for competitive intelligence and marketing analysts”, European Journal of Marketing, Vol. 42 Nos 7/8, pp. 804-813.

Mikalef, P., Boura, M., Lekakos, G. and Krogstie, J. (2019), "Big data analytics capabilities and innovation: the mediating role of dynamic capabilities and moderating effect of the environment", British Journal of Management, Vol. 30 No. 2, pp. 272-298, doi: 10.1111/1467-8551.12343.

Miller, D. and Friesen, P. (1980), "Momentum and revolution in organizational adaptation", Academy of Management Journal, Vol. 23 No. 4, pp. 591-615.

Mingers, J. and Willcocks, L. (2017), “An integrative semiotic methodology for is research”, Information and Organization, Vol. 27 No. 1, pp. 17-36, doi: 10.1016/j.infoandorg.2016.12.001.

Mintzberg, H. (1973), The Nature of Managerial Work, Harper and Row, New York, NY.

Moorman, C., Zaltman, G. and Deshpandé, R. (1992), "Relationships between providers and users of market research: the dynamics of trust within and between organizations", Journal of Marketing Research, Vol. 29 No. 3, pp. 314-329.

Mora, M., Forgionne, G., Gupta, J., Cervantes, F. and Gelman, O. (2005), “A strategic research agenda”, Journal of Decision Systems, Vol. 14 Nos 1/2, pp. 179-196, doi: 10.3166/jds.14.179-196.

Moro, S.S., Cortez, P. and Rita, P. (2015), "Business intelligence in banking: a literature analysis from 2002 to 2013 using text mining and latent Dirichlet allocation", Expert Systems with Applications, Vol. 42 No. 3, pp. 1314-1324, doi: 10.1016/j.eswa.2014.09.024.

Morris, H., Harvey, C. and Kelly, A. (2009), "Journal rankings and the ABS journal quality guide", Management Decision, Vol. 47 No. 9, pp. 1441-1451, doi: 10.1108/00251740910995648.

Müller, S.D. and Jensen, P. (2017), "Big data in the Danish industry: application and value creation", Business Process Management Journal, Vol. 23 No. 3, pp. 645-670, doi: 10.1108/BPMJ-01-2016-0017.

Narver, J.C. and Slater, S.F. (1990), "The effect of a market orientation on business profitability”, Journal of Marketing, Vol. 54 No. 4, pp. 20-34.

O'Reilley, C. and Tushman, M. (2002), Winning through Innovation: A Practical Guide to Leading Organizational Change and Renewal, Harvard Business School Press, Cambridge, MA.

Opait, G., Bleoju, G., Nistor, R. and Capatina, A. (2016), "The influences of competitive intelligence budgets on informational energy dynamics", Journal of Business Research, Vol. 69 No. 5, pp. 1682-1689, doi: 10.1016/j.jbusres.2015.10.038.

Pawar, B.S. and Sharda, R. (1997), "Obtaining business intelligence on the internet", Long Range Planning, Vol. 30 No. 1, pp. 110-121.

Peyrot, M., Childs, N., Van Doren, D. and Allen, K. (2002), "An empirically based model of competitor intelligence use", Journal of Business Research, Vol. 55 No. 9, pp. 747-758.

Peyrot, M., Van Doren, D., Allen, K. and Childs, N. (1996), “Competitor intelligence among industrial wholesalers: an exploratory study", Journal of Marketing Management, Vol. 6, pp. 46-60.

Pfeffer, J. and Salancik, G.R. (1978), The External Control of Organizations: A Resource Dependence Perspective, Harper and Row, New York, NY.

Popovič, A., Hackney, R., Coelho, P.S. and Jaklič, J. (2012), "Towards business intelligence systems success: effects of maturity and culture on analytical decision making", Decision Support Systems, Vol. 54 No. 1, pp. 729-739.

Porac, J.F. and Thomas, H. (1990), "Taxonomic mental models in competitor definition", Academy of Management Review, Vol. 15 No. 2, pp. 224-240. 
Prescott, J. and Smith, D. (1987), “A project-based approach to competitive analysis”, Strategic Management Journal, Vol. 8 No. 5, pp. 411-423.

Pryor, C., Holmes, R.M., Webb, J.W. and Liguori, E.W. (2019), "Top executive goal orientations' effects on environmental scanning and performance: differences between founders and nonfounders", Journal of Management, Vol. 45 No. 5, pp. 1958-1986, doi: 10.1177/0149206317737354.

Qiu, T. (2008), "Scanning for competitive intelligence: a managerial perspective", European Journal of Marketing, Vol. 42 Nos 7/8, pp. 814-835.

Rajagopalan, N., Rasheed, A.M.A. and Datta, D.K. (1993), "Strategic decision processes: critical review and future directions", Journal of Management, Vol. 19 No. 2, pp. 349-384, doi: 10.1177/ 014920639301900207.

Ramakrishnan, T., Jones, M.C. and Sidorova, A. (2012), "Factors influencing business intelligence (BI) data collection strategies: an empirical investigation”, Decision Support Systems, Vol. 52 No. 2, pp. 486-496.

Reinmoeller, P. and Ansari, S. (2016), "The persistence of a stigmatized practice: a study of competitive intelligence”, British Journal of Management, Vol. 27 No. 1, pp. 116-142, doi: 10.1111/1467-8551.12106.

Robinson, C.V. and Simmons, J.E.L. (2017), "Organising environmental scanning: exploring information source, mode and the impact of firm size”, Long Range Planning, Vol. 51 No. 4, doi: 10.1016/j. lrp.2017.10.004.

Roden, S., Nucciarelli, A., Li, F. and Graham, G. (2017), "Big data and the transformation of operations models: a framework and a new research agenda”, Production Planning and Control, Vol. 28 Nos 11/12, pp. 929-944, doi: 10.1080/09537287.2017.1336792.

Rouach, D. and Santi, P. (2001), "Competitive intelligence adds value: five intelligence attitudes", European Management Journal, Vol. 19 No. 5, pp. 552-559, doi: 10.1016/S0263-2373(01)00069-X.

Sawyerr, O. (1993), "Environmental uncertainty and environmental scanning activities of Nigerian manufacturing executives: a comparative analysis”, Strategic Management Journal, Vol. 14 No. 4, pp. 287-299.

Seddon, P.B., Constantinidis, D., Tamm, T. and Dod, H. (2016), "How does business analytics contribute to business value?”, Information Systems Journal, Vol. 27 No. 3, pp. 237-269, doi: 10.1111/isj.12101.

Sen, A. and Sinha, A.P. (2005), "A comparison of data warehousing methodologies", Communications of the Acm, Vol. 48 No. 3, pp. 79-84.

Sharma, R., Mithas, S. and Kankanhalli, A. (2014), "Transforming decision-making processes: a research agenda for understanding the impact of business analytics on organisations", European Journal of Information Systems, Vol. 23 No. 4, pp. 433-441.

Sheng, Y.P., Mykytyn, P.P.J. and Litecky, C.R. (2005), "Competitor analysis and its defenses in the e-marketplace", Communications of the ACM, Vol. 48 No. 8, pp. 107-112.

Shim, J.P., Warkentin, M., Courtney, J.F., Power, D.J., Sharda, R. and Carlsson, C. (2002), "Past, present, and future of decision support technology", Decision Support Systems, Vol. 33 No. 2, pp. 111-126, doi: 10.1016/S0167-9236(01)00139-7.

Shollo, A. and Galliers, R.D. (2015), "Towards an understanding of the role of business intelligence systems in organisational knowing”, Information Systems Journal, Vol. 26 No. 4, pp. 339-367, doi: 10.1111/isj.12071.

Singh, S.K., Watson, H. and Watson, R. (2002), "EIS support for the strategic management process", Decision Support Systems, Vol. 33 No. 1, pp. 71-85.

Sivarajah, U., Kamal, M.M., Irani, Z. and Weerakkody, V. (2017), "Critical analysis of big data challenges and analytical methods", Journal of Business Research, Vol. 70, pp. 263-286, doi: 10.1016/j.jbusres.2016.08.001.

Slater, S. and Narver, J. (2000), "Intelligence generation and superior customer value", Journal of the Academy of Marketing Science, Vol. 28 No. 1, pp. 120-127.

Srivastava, J. and Cooley, R. (2003), "Web business intelligence: mining the web for actionable knowledge”, INFORMS Journal on Computing, Vol. 15 No. 2, pp. 191-207. 
MRR 44,5

Talaoui, Y. and Kohtamäki, M. (2020), "Of BI research: a tale of two communities”, Management Research Review, Vol. 43 No. 11, pp. 1371-1394.

Tanev, S. and Bailetti, T. (2008), "Competitive intelligence information and innovation in small Canadian firms”, European Journal of Marketing, Vol. 42 Nos 7/8, pp. 786-803.

Taylor, J.W. (1992), "Competitive intelligence: a status report on US business practices", Journal of Marketing Management, Vol. 8 No. 2, pp. 117-125.

Thennakoon, D., Bandara, W., French, E. and Mathiesen, P. (2018), "What do we know about business process management training? Current status of related research and a way forward", Business Process Management Journal, Vol. 24 No. 2, pp. 478-500, doi: 10.1108/BPMJ-09-2016-0180.

Thomas, A., Litschert, R. and Ramaswamy, K. (1991), "The performance impact of strategy manager coalignment: an empirical examination”, Strategic Management Journal, Vol. 12 No. 7, pp. 509-522.

Toit, A.S.A. (2015), "Competitive intelligence research: an investigation of trends in the literature", Journal of Intelligence Studies in Business, Vol. 5 No. 2, pp. 14-21.

Trieu, V.H. (2017), "Getting value from business intelligence systems: a review and research agenda", Decision Support Systems, Vol. 93, pp. 111-124, doi: 10.1016/j.dss.2016.09.019.

Trim, R.J. and Lee, P.Y.I. (2008), “A strategic marketing intelligence and multi-organisational resilience framework”, European Journal of Marketing, Vol. 42 Nos 7/8, pp. 731-745.

Turban, E. and Schaeffer, D. (1987), “A comparative study of executive information systems”, DSS 87 Transactions, pp. 139-148.

Turban, E., King, D., and Lang, J. (2010), Introduction to Electronic Commerce, Prentice Hall, New York, NY.

Urbinati, A., Bogers, M., Chiesa, V. and Frattini, F. (2019), "Creating and capturing value from big data: a multiple-case study analysis of provider companies", Technovation, Vol. 84-85, pp. 21-36, doi: 10.1016/j.technovation.2018.07.004.

Vaara, E. and Lamberg, J.A. (2014), "Academy of management review”, Taking Historical Embeddedness Seriously: Three Historical Approaches to Advance Strategy Process and Practice Research EERO.

Van De Ven, A.H. (1992), "Suggestions for studying strategy process: a research note Andrew", Strategic Management Journal, Vol. 13, pp. 169-188, doi: 10.1080/02566702.1990.9648237.

Vedder, R.G., Vanecek, M.T., Guynes, S.C. and Cappel, J.J. (1999), "CEO and CIO perspectives on competitive intelligence", Communications of the ACM, Vol. 42 No. 8, pp. 108-116.

Viaene, S., Bunder, A. and Van den, (2011), "The secrets to managing business analytics projects", MIT Sloan Management Review, Vol. 53 No. 1, pp. 65-69.

Vidgen, R., Shaw, S. and Grant, D.B. (2017), "Management challenges in creating value from business analytics", European Journal of Operational Research, Vol. 261 No. 2, pp. 626-639.

Vogel, R. (2012), "The visible colleges of management and organization studies: a bibliometric analysis of academic journals", Organization Studies, Vol. 33 No. 8, pp. 1015-1043.

Walters, B.A., Jiang, J.J. and Klein, G. (2003), "Strategic information and strategic decision making: the EIS/CEO interface in smaller manufacturing companies", Information and Management, Vol. 40 No. 6, pp. 487-495.

Wamba, S.F., Gunasekaran, A., Akter, S., Fan Ren, S.J., Dubey, R. and Childe, S.J. (2017), "Big data analytics and firm performance: effects of dynamic capabilities", Journal of Business Research, Vol. 70, pp. 356-365, doi: 10.1016/j.jbusres.2016.08.009.

Wang, C.H., Cheng, H.Y. and Deng, Y.T. (2018b), "Using Bayesian belief network and time-series model to conduct prescriptive and predictive analytics for computer industries", Computers and Industrial Engineering, Vol. 115, pp. 486-494.

Wang, Y., Kung, L.A., Wang, W.Y.C. and Cegielski, C.G. (2018a), "An integrated big data analyticsenabled transformation model: application to health care", Information and Management, Vol. 55 No. 1, pp. 64-79, doi: 10.1016/j.im.2017.04.001. 
Watson, H.J. (2009), “Tutorial: business intelligence - past, present, and future”, Communications of the Association for Information Systems, Vol. 25, pp. 487-510, available at: http://aisel.aisnet.org/ cais/vol25/iss1/39/

Watson, H.J. and Wixom, B. (2007), "The current state of business intelligence in academia”, Computer, Vol. 40 No. 9, pp. 299-312, doi: 10.1109/MC.2007.331.

Webster, J. and Watson, R.T. (2002), “Analyzing the past to prepare for the future: writing a literature review”, MIS Quarterly, Vol. 26 No. 2, pp. 13-23.

Wei, C. and Lee, Y. (2004), "Event detection from online news documents for supporting environmental scanning", Decision Support Systems, Vol. 36 No. 4, pp. 385-401.

Wright, S., Eid, E. and Fleisher, C. (2009), "Competitive intelligence in practice: empirical evidence from the UK retail banking sector", Journal of Marketing Management, Vol. 25 Nos 9/10, pp. 941-964.

Xu, K., Liao, S.S., Li, J. and Song, Y. (2011), "Mining comparative opinions from customer reviews for competitive intelligence", Decision Support Systems, Vol. 50 No. 4, pp. 743-754.

Yasai-Ardekani, M. and Nystrom, P. (1996), "Designs for environmental scanning systems: tests of a contingency theory”, Management Science, Vol. 42 No. 2, pp. 187-207.

Zajac, E.J. and Bazerman, M.H. (1991), "Blind spots in industry and competitor analysis: implications of interfirm (mis)perceptions for strategic decisions", Academy of Management Review, Vol. 16 No. 1, doi: 10.5465/AMR.1991.4278990.

Zeithaml, V.A. (1988), "Consumer perception of price, quality, and value: a means-end model and synthesis of evidence", Journal of Marketing, Vol. 52 No. 3, pp. 2-22.

Zheng, Z.E., Fader, P. and Padmanabhan, B. (2012), "From business intelligence to competitive intelligence: inferring competitive measures using augmented site- centric data", Information Systems Research Publication, Vol. 23, pp. 698-720.

Zhu, K. and Kraemer, K.L. (2005), "Post-adoption variations in usage and value of e-business by organizations: cross-country evidence from the retail industry", Information Systems Research, Vol. 16 No. 1, pp. 61-84.

\begin{abstract}
About the authors
Yassine Talaoui is a researcher at the School of Management at the University of Vasa, where he teaches business models and strategic management theories. His research interests focus on delineating relationships between materiality, digitization and management and organization studies. He is the recipient of the 2018 SAP Interest Group Division Pushing The Boundary Award at the Academy of Management. Yassine Talaoui is the corresponding author and can be contacted at: yassine.talaoui@uva.fi

Marko Kohtamäki $(\mathrm{PhD})$ is a Professor of Strategy at the University of Vaasa, and a visiting professor at the University of South-Eastern Norway, USN Business School and Luleå University of Technology. Kohtamäki takes special interest in strategic practices, strategic agility and business intelligence. Kohtamäki has published in distinguished international journals such as Strategic Management Journal, International Journal of Operations and Production Management, Industrial Marketing Management, Long Range Planning, Strategic Entrepreneurship Journal, International Journal of Production Economics, Technovation, Journal of Business Research, amongst others.
\end{abstract}

For instructions on how to order reprints of this article, please visit our website: www.emeraldgrouppublishing.com/licensing/reprints.htm Or contact us for further details: permissions@emeraldinsight.com 